Old Dominion University

ODU Digital Commons

Civil \& Environmental Engineering Faculty

Publications

Civil \& Environmental Engineering

2021

\title{
The Influence of Channel Deepening on Tides, River Discharge Effects, and Storm Surge
}

\author{
S. A. Talke \\ Ramin Familkhalili \\ Old Dominion University, rfamilkh@odu.edu \\ D. A. Jay
}

Follow this and additional works at: https://digitalcommons.odu.edu/cee_fac_pubs

Part of the Environmental Engineering Commons, and the Transportation Engineering Commons

\section{Original Publication Citation}

Talke, S. A., Familkhalili, R., \& Jay, D. A. (2021). The influence of channel deepening on tides, river discharge effects, and storm surge. Journal of Geophysical Research: Oceans, 126(5), Article e2020JC016328, 1-24. https://doi.org/10.1029/2020JC016328

This Article is brought to you for free and open access by the Civil \& Environmental Engineering at ODU Digital Commons. It has been accepted for inclusion in Civil \& Environmental Engineering Faculty Publications by an authorized administrator of ODU Digital Commons. For more information, please contact digitalcommons@odu.edu. 


\section{JGR Oceans}

\section{RESEARCH ARTICLE \\ 10.1029/2020JC016328 \\ Key Points: \\ - Tidal range amplifies after channel deepening in a strongly frictional estuary, with a peak increase near the damping lengthscale \\ - Storm surge amplitudes evolve similarly to tides, with a similar spatial pattern and location of maximum change \\ - Extreme water levels caused by rive discharge have likely decreased due to bathymetric change}

Supporting Information:

Supporting Information may be found in the online version of this article.

Correspondence to:

S. A. Talke,

stalke@calpoly.edu

Citation:

Talke, S. A., Familkhalili, R., \& Jay, D. A. (2021). The influence of channel deepening on tides, river discharge effects, and storm surge. Journal of Geophysical Research: Oceans, 126, e2020JC016328. https://doi org/10.1029/2020JC016328

Received 16 APR 2020 Accepted 22 APR 202

(C) 2021. American Geophysical Union. All Rights Reserved.

\section{The Influence of Channel Deepening on Tides, River Discharge Effects, and Storm Surge}

\author{
S. A. Talke ${ }^{1}\left(\mathbb{D}\right.$, R. Familkhalili ${ }^{2}$ (D) and D. A. Jay ${ }^{3}$ (D) \\ ${ }^{1}$ Civil and Environmental Engineering, California Polytechnic State University, San Luis Obispo, CA, USA, ${ }^{2}$ Civil and \\ Environmental Engineering, Old Dominion University, Norfolk, VA, USA, ${ }^{3}$ Civil and Environmental Engineering, \\ Portland State University, Portland, OR, USA
}

Abstract We combine archival research, semi-analytical models, and numerical simulations to address the following question: how do changes to channel geometry alter tidal properties and flood dynamics in a hyposynchronous, strongly frictional estuary with a landward decay in tidal amplitudes? Records in the Saint Johns River Estuary since the 1890s show that tidal range has doubled in Jacksonville, Florida. Near the estuary inlet, tidal discharge approximately doubled but tidal amplitudes increased only $\sim 6 \%$. Modeling shows that increased shipping channel depths from $\sim 5$ to $\sim 13 \mathrm{~m}$ drove the observed changes, with other factors like channel shortening and width reduction producing comparatively minor effects. Tidal amplitude increases are spatially variable, with a maximum change $20-25 \mathrm{~km}$ from the estuary inlet; tidal theory suggests that increases in amplitude approximately follow $x \exp (\mu x)$, where $x$ is the distance from the ocean and $\mu$ is a damping coefficient. Tidal changes are a predictor of altered surge dynamics: Numerical modeling of hurricane Irma under 1898 and 2017 bathymetric conditions confirms that both tidal and storm surge amplitudes are larger today, with a similar spatial pattern. Nonetheless, peak water levels are simulated to be larger under 1898 bathymetry. The cause is likely the record river discharge observed during the storm; as suggested by a subtidal water-level model, channel deepening since 1898 appears to have reduced the average surface slope required to drain both mean river flow and storm flows toward the ocean. Nonetheless, results suggest an increased vulnerability to storms with less river flow, but larger storm surge.

Plain Language Summary In this study, we evaluate whether channel deepening and other geometric changes have altered the effects of tides, storm surge, and river flow within the lower Saint Johns River Estuary, Florida, USA. Using data from archives and old reports, we find that tidal range has more than doubled in some locations since the late 1800s. Further, the average water level difference between Jacksonville, Florida and the coast appears to have decreased, while tidal velocities and discharge have increased. Numerical and analytical models show that the primary cause is channel deepening and dredging; other factors, such as shortening the channel, have comparatively minor influence. Using the numerical model, we simulated the effects of hurricane Irma under both modern and historic (1900 Era) geometry. Results show that the storm surge from hurricane Irma was higher today than it would have been a century ago. However, overall water levels in Jacksonville were simulated to be $0.2 \mathrm{~m}$ less today than historically, since the deeper channel enabled the record amount of rainfall, runoff, and windinduced currents from the storm to exit toward the ocean more easily. Hence, anthropogenic development of estuarine waterways can both decrease the hazard from river-based floods, while increasing the marinesourced hazard.

\section{Introduction}

Shipping channels in many estuaries around the world have been deepened by a factor of two or more since the mid-19th century, with deep-draft ships requiring increasingly wide and deep shipping channels (e.g., Talke \& Jay, 2020; Winterwerp et al., 2013). At the same time, channelization, reclamation, and diking has often reduced connectivity to wetlands and reduced estuary width. Consequences include increased salinity intrusion (e.g., Ralston \& Geyer, 2019), altered tidal velocities (e.g., Pareja-Roman et al., 2020) and an upstream movement of the estuary turbidity maximum (see review by Burchard et al., 2018, and references therein). Reduced frictional resistance in a deeper channel leads to reduced damping of long-wave energy. 
Depth changes also alter resonance effects and can lead to either amplification or attenuation of tidal amplitudes (Talke \& Jay, 2020), particularly if a total reflection occurs at the head of an estuary. Convergence and width changes also influence tidal amplitudes (Friedrichs \& Aubrey, 1994; Jay, 1991).

The combination of frictional and resonance effects have sometimes resulted in a doubling (or more) of tidal range in up-river locations (Talke \& Jay, 2020; Winterwerp \& Wang, 2013). Since storm surge is a shallow-water wave with a similar amplitude and time scale as a tide wave, the same anthropogenic alterations can produce similar increases in storm surge magnitudes (Familkhalili \& Talke, 2016; Ralston et al., 2019). Nonetheless, decreased frictional effects can lead to a decrease in mean (tidally averaged) water levels for a given river flow, due to a reduced subtidal slope in the water surface (Jay et al., 2011; Jensen et al., 2003; Ralston et al., 2019). Because the same process (channel deepening) can amplify long-wave heights but decrease the tidally averaged water level, it remains unclear whether channel deepening will produce higher or lower total water levels for any given storm event at a given location (combined tides, surge, local wind setup, precipitation, and river flow).

In this contribution we study an estuary known to be sensitive to channel dredging. Numerical simulations of the lower Saint Johns River Estuary (SJRE) suggest that future sea-level rise and presently-occurring channel deepening to $14.3 \mathrm{~m}$ will likely increase tidal range on the order of $0-0.1 \mathrm{~m}$ within the channel (Bilskie, 2013; Hagen et al., 2013), and increase the 50-100 year storm tide by 0-0.2 m (USACE, 2014). These changes, along with other environmental effects such as increased salinity intrusion (Bellino \& Spechler, 2013; Mulamba et al., 2019), show that the region is sensitive to anthropogenic modification. Given that historical shipping channel depths have increased from perhaps $3 \mathrm{~m}$ pre-1870 to $\sim 12.2 \mathrm{~m}$ today, the SJRE is a good test bed for examining mechanisms of change and likely results of deepening.

The use of the Saint Johns River estuary as a case study is further motivated by a historical conundrum. On October 2, 1898, a category 4 hurricane made landfall just north of the Florida/Georgia border, severely flooding the town of Fernandina (Monthly Weather Review, 1898) and producing a water level of $2.6 \mathrm{~m}$ (relative to the NAVD-88 datum) at the mouth of the Saint Johns River, located $35 \mathrm{~km}$ south (Figure 1; Sandrik \& Jarvinen, 1999). Nonetheless, damage in the city of Jacksonville, located $\sim 40 \mathrm{~km}$ inland along the Saint Johns River, was minor (Monthly Weather Review, 1898). By contrast, storm surge from hurricane Irma on September 11, 2017 caused record flooding in Jacksonville and nearby regions (e.g., Monroe \& Hong, 2018), even though the water levels of $1.7 \mathrm{~m}$ measured at the estuary inlet (relative to NAVD-88 datum) were significantly lower than in 1898. Though many factors influence flooding, including the built environment and the meteorological characteristics of each particular storm (rainfall, storm track, wind field, and pressure), we focus here on the water level effects of bathymetric change. Specifically, we ask three related questions:

- Did channel deepening, streamlining, and other anthropogenic changes to the Saint Johns River reduce the natural protection against storm surge that the shallower channel of 1898 provided, increasing the vulnerability of inland regions to marine-sourced flooding?

- Did these same changes facilitate drainage of precipitation run-off to the ocean, reducing the hazard of the river flood wave?

- What is the net effect of these landscape changes on water levels, during both typical and storm conditions?

Our case-study approach provides insights into how tides, tidal discharge, mean water levels, and storm surge in similar hyposynchronous estuaries-highly frictional and marked by tides that strongly decay in the landward direction-might react to anthropogenic modifications such as channel deepening. We employ a combination of archival data rescue, semi-analytical modeling, and numerical modeling to obtain new insights into the long-term trajectory of change, and its cause. Archival tidal records from as early as the 1890s are digitized and used to quantify spatially variable changes to tidal range and estimate river slope. A semi-analytical model is used to explore how depth and other geometric variations influence both tidal and subtidal properties. Finally, we use numerical simulations based on 1898 and 2014 bathymetry to explore how storm surge and peak water levels during hurricane Irma (2017) were affected by bathymetric change. 
a)

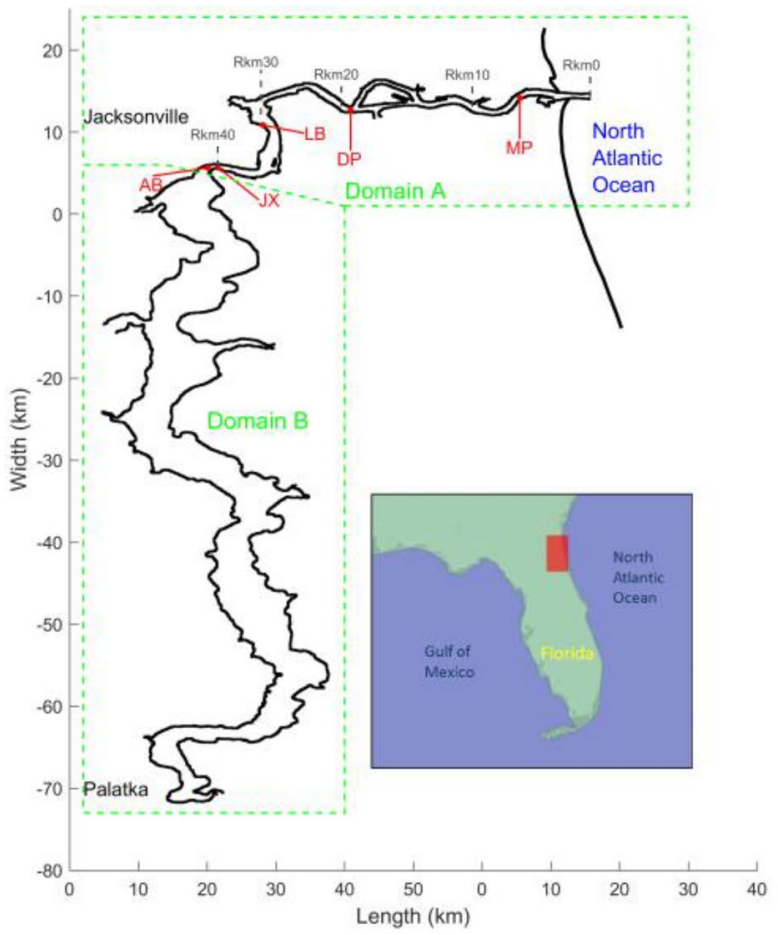

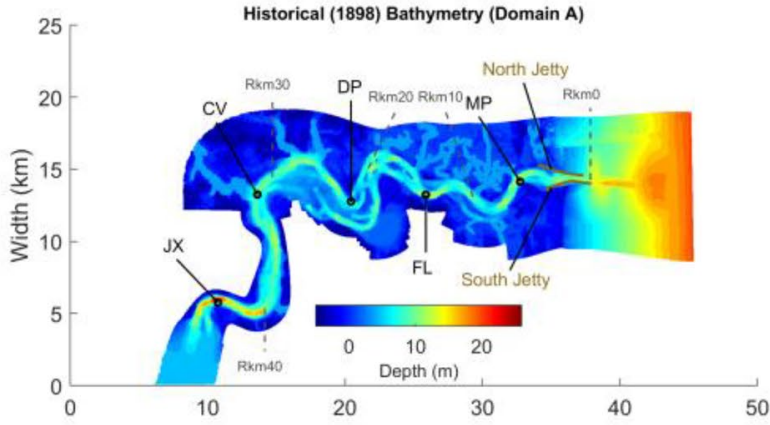

c)

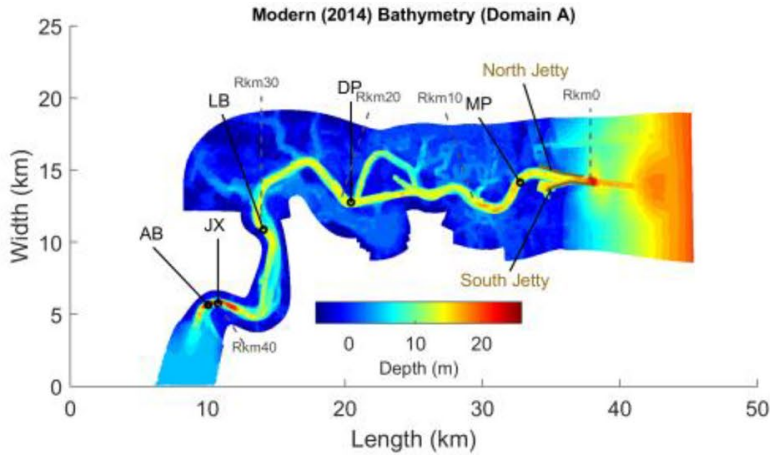

Figure 1. (a) Site map of the Saint Johns River Estuary, Florida, with (b) Historic (1898) and (c) Modern (2014) bathymetry depicted from the ocean to Jacksonville. Abbreviations as follows: AB = Acosta Bridge, USGS gage 02246500, JX = Jacksonville, NOAA gage 8720226, LB = Long Branch, NOAA gage 8720242, DP = Dames Point, NOAA gage 8720219, MP = Mayport, NOAA gage 8720218. NOAA = National Oceanographic and Atmospheric Administration; USGS = United States Geological Survey.

\section{Setting and Methods}

\subsection{Setting and Bathymetric Change}

The Saint Johns River, Florida, is a microtidal estuary with primarily semidiurnal tides. Tidal range decreases from $\sim 1.5 \mathrm{~m}$ at the ocean inlet to approximately $0.55 \mathrm{~m}$ in the city of Jacksonville, located $40 \mathrm{~km}$ upstream. The estuary is heavily channelized and diked over its first $40 \mathrm{~km}$. A large, shallow bay extends southward from Jacksonville for $85 \mathrm{~km}$, with a typical width between 2 and $5 \mathrm{~km}$ and a controlling channel depth of 4.5 to $6 \mathrm{~m}$ (Figure 1; National Oceanographic and Atmopsheric Administration [NOAA] chart 11492). Tides propagate southwards from Jacksonville along the tidal river until finally dissipating more than $100 \mathrm{~km}$ upstream (Henrie \& Valle-Levinson, 2014). The average river discharge from the nearly $23,000 \mathrm{~km}^{2}$ watershed for the years 1971-2017 was $\sim 200 \mathrm{~m}^{3} / \mathrm{s}$ (see also Bellino \& Spechler, 2013). A record tidally filtered flow of just over $4,000 \mathrm{~m}^{3} / \mathrm{s}$ was estimated by the United States Geological Survey (USGS) on September 12, 2017 (USGS gauge 02246500), approximately 1 day after the peak storm surge from hurricane Irma.

Over the past 150 years, the shipping channel in the Saint Johns River has been deepened from a controlling depth of 6-10 feet (1.8-3 m) to a depth that varies between 41 and 50 feet (12.5-15.2 m; NOAA Chart 1149102-2015) relative to Mean-Lower-Low Water (MLLW). Modest dredging that totaled 75-80,000 cubic meters was begun in the 1870 s to develop and maintain a $10 \mathrm{ft}$. $(3 \mathrm{~m})$ deep, $80 \mathrm{ft}$. $(24.4 \mathrm{~m})$ wide shipping channel (Kingman et al., 1915). Construction of an entrance jetty to scour the mouth began in the 1880s, and the jetties currently extend $\sim 2 \mathrm{~km}$ into the ocean. Such channelization and dredging efforts increased the controlling depth to 3.7-4.6 m (12-15) feet in the early 1890s (USACE, 1893). By 1900, a shipping channel of $18 \mathrm{ft}$. (5.5 m) was dredged nearly to Jacksonville (e.g., NOAA chart 454A-12-1899), and diking of wetlands had begun. The scale of dredging increased in the early 20th century, and by 1915 the channel to Jacksonville was reported to be 7.9-9.1 m (26-30 ft.; NOAA chart 577-00-1917). In 1952, the shipping channel was shortened by $3 \mathrm{~km}$ by cutting through a wetland located just downstream of Dames Point (See Figure 1). 


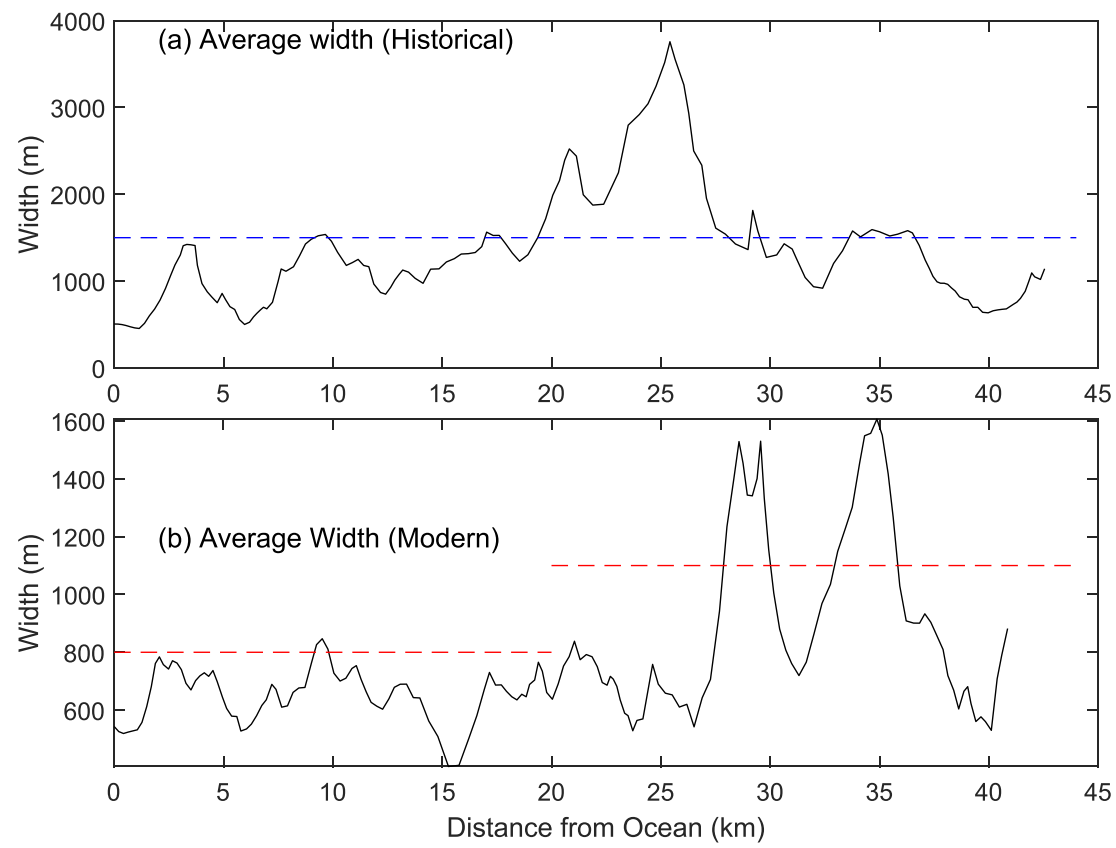

Figure 2. Measured width in (a) 1898 and (b) 2014 bathymetry, for a cross-section that extends between the MLW datum located on either side of the channel thalweg. The dashed line indicates the depth used in the idealized tide and river discharge models.

An additional kilometer of length was removed near the Longbranch neighborhood of Jacksonville at River kilometer (Rkm) 30 (see Figure 1b with Figure 1c, or Supplemental Information). By 1959, channel depths varied from $9.1 \mathrm{~m}$ ( $30 \mathrm{ft}$., in Jacksonville) to $12.2 \mathrm{~m}$ (40 ft., at entrance) relative to MLLW, with a dredged width between 122 to $366 \mathrm{~m}$ (400-1200 ft.). A history of changes is available in Rawls (1952). Plans are currently being implemented to further dredge to $14.3 \mathrm{~m}$ (47 ft.; USACE, 2014).

To enable numerical modeling of the 1890s era (see Section 2.5), we digitized available bathymetry from 1898 from the coastal ocean to just upstream of Jacksonville (NOAA chart 454A-12-1899). For modern bathymetry, we obtained a digital elevation model from 2014 from NOAA/NOS (National Oceanic and Atmospheric Administration/National Ocean Survey) (see Figure 1). Further information about the location and depth of tributary channels was taken from additional charts available at https://historicalcharts.noaa.gov. Because both historical and modern bathymetric surveys typically only include data below Mean Low Water, wetland bathymetry from a Lidar survey with $5 \mathrm{~m}$ resolution was obtained from NOAA (https://coast. noaa.gov/digitalcoast/data). The areal extent of wetlands near the coast appears to be similar in both the historical and modern maps, except near the industrial corridor around the shipping channel. Therefore, due to a lack of historical wetland bathymetry, we use the modern Lidar data as a proxy for the historical floodplain.

Based on an analysis of the digital elevation models, the flow-carrying width has been narrowed, with the median width in the modern system about $40 \%$ less than in the 1890s (Figure 2). At the same time, the cross-sectionally averaged depth has slightly more than doubled (Figure 3). The measured width decrease is due to land reclamation and diking, and stems from our definition of the flow-carrying width (Figure 2), which we measure between the Mean Low Water lines at the side of the channel. Over the same time period, the width of the shipping channel increased, as described above. The average depth was calculated by dividing the cross-sectional area by the width (Figure 3).

\subsection{Data}

We use a combination of historical and modern records to elucidate the effects of bathymetric changes on tidal properties. A continuous hourly record of water level is available from Mayport since 1928, from 

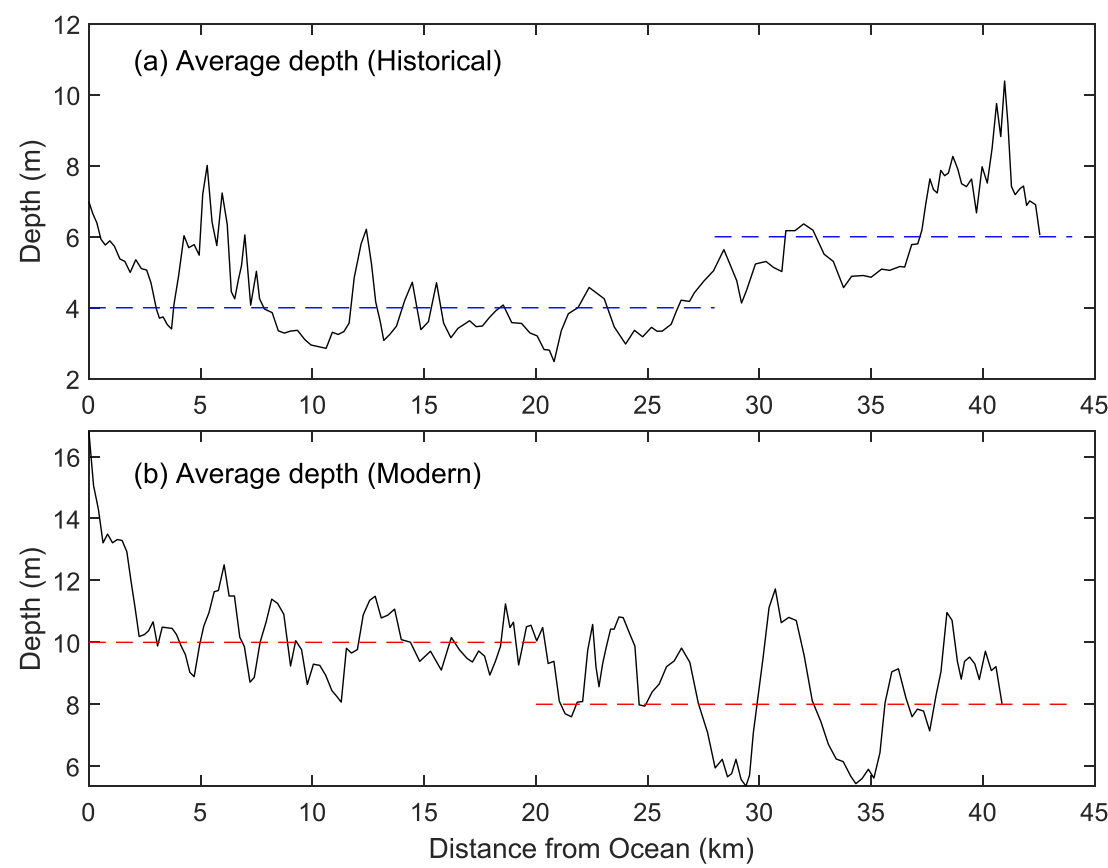

Figure 3. Average estimated depth in (a) 1898 and (b) 2014 bathymetry, obtained by dividing the cross-sectional area by the cross-sectional width. Datum is mean sea-level. The dashed line indicates the depth used in the idealized tide and river discharge models.

a composite of NOAA gauges 8720218 and 8720220. Modern NOAA data for Dames Point (station number 8720219; 1998-present, intermittent), the Longbranch neighborhood of Jacksonville (station 8720242; 1998-2003, intermittent) and Jacksonville (station 8720226; 1997-present, intermittent) are also used in our analysis (see Figure 1 for locations). The USGS has also measured water levels and discharge near the Acosta Bridge in Jacksonville since 1945, but only records since 1970 are available (station 02246500). Though the USGS and NOAA gauges in Jacksonville are less than $1 \mathrm{~km}$ apart, they measured peak water levels that were approximately $0.15 \mathrm{~m}$ different (relative to NAVD-88 datum) during Hurricane Irma. The reason is unknown, but could include gauge error or substantial local variability in water levels.

Archives and old reports yielded substantial information about historical tidal conditions (see Supplemental Information Section S.2). Synopses of tidal measurements from 1879, 1889, and 1892 were found in the annual reports of the United States Army Corps of Engineers (Gieseler, 1893; USACE 1879, 1892). Additional extracts of measurements taken between the 1850s and early 1900s were found in summary sheets of the United States Coast and Geodetic Survey (USCG\&S, Record Group 23, United States National Archives). Monthly mean tide level and mean tidal range for Mayport, Florida for 1895-1897 are available from NOAA (station 8720220). Historical measurements of tidal range are converted to an $\mathrm{M}_{2}$ estimate by dividing by 2.07, the ratio observed in modern measurements. An estimate of mean water level for Jacksonville for the year 1892 relative to the North American Vertical Datum of 1988 (NAVD-88) was found using the tabulated height of mean high and low water relative to local benchmarks (see Supplemental Information Section S.2.4).

Hourly and high/low tidal records were also found, recovered, digitized, and quality assured (see also Talke \& Jay, 2017), as summarized in Supplemental Table S.1. Three years of hourly data from Mayport (18951897) were recovered from the United States National Archives and digitized. Tidal records from 1928 to 1935 and 1953 to 1968 from Longbranch ( $\mathrm{Rkm}$ 30) were found in the EV2 database from the National Centers for Environmental Information (https://www.ncdc.noaa.gov/EdadsV2/); selected high/low data and summary statistics such as mean tidal range and mean sea level were digitized. The datum for the 1929-1935 and 1953-1968 series was tied to the NAVD-88 datum through an extant benchmark (see supplement S.2.3). A short NOAA record from Acosta Bridge for the year 1959 was also digitized. 


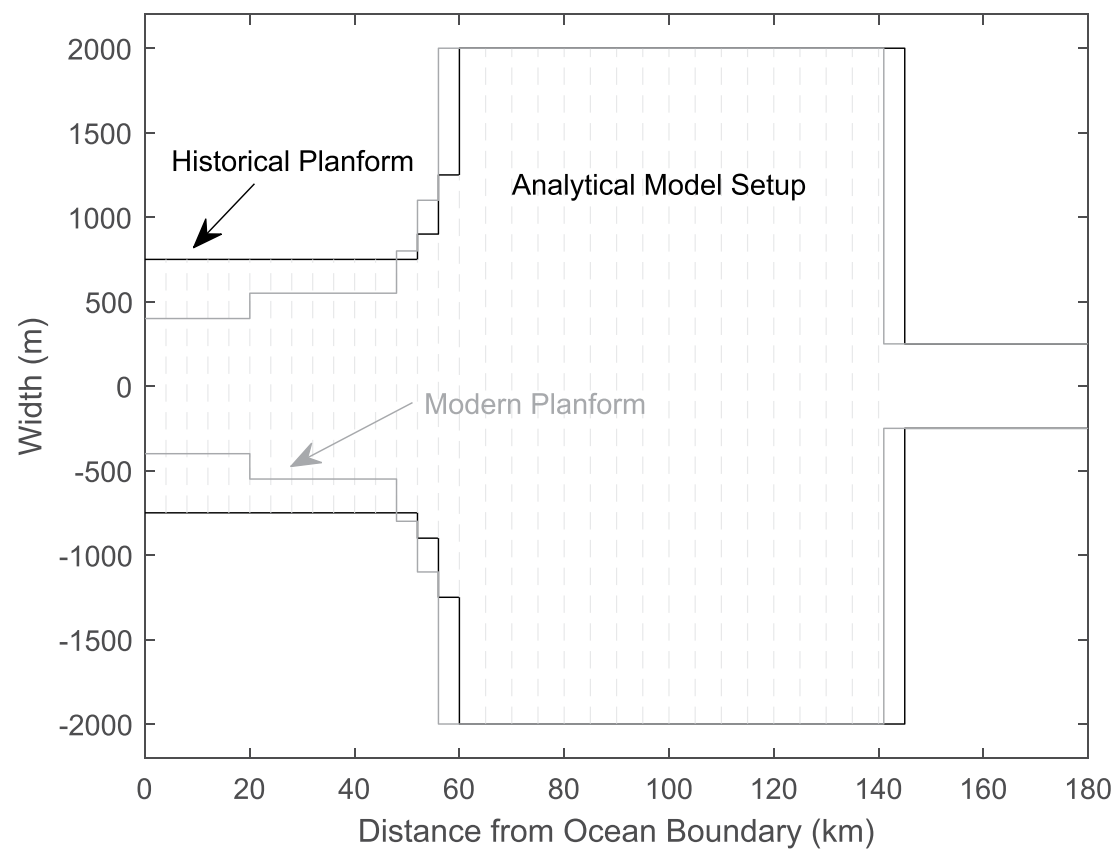

Figure 4. Planform of the idealized tidal channel model developed in Section 2.3, for both the historical and modern configurations. The channel at the right hand side extends an additional $\sim 100 \mathrm{~km}$ to enable the tide to damp out.

Historical estimates of cross-sectionally-averaged discharge at six locations are available between Mayport and Rkm 30 from Gieseler (1893), based on 9 days of measurements at Mayport between August 12 and August 23, 1892. Estimates upstream of Mayport were approximated by calculating tidal prism from tidal measurements. We adjusted the averaged flood/ebb discharges to an $\mathrm{M}_{2}$ amplitude by assuming an equivalent sinusoidal discharge. Although these measurements must be considered approximate, they show good agreement with modeling (see Results) and therefore help ground-truth results. A modern estimate of the $\mathrm{M}_{2}$ discharge amplitude was obtained through harmonic analysis (Pawlowicz et al., 2002) of USGS discharge data at Jacksonville over the period of record.

\subsection{Semi-Analytical Tidal Model}

To help interpret water level changes evident in archival records (see results), we develop an idealized analytical tidal model (this section) and subtidal model (Section 2.4). The width, depth and planform of both models are presented in Figures 2-4. The modern and historical system between the ocean and Jacksonville are approximated as two constant width and depth channels (see dashed lines in Figures 2 and 3), and reflect the observation that there is no clear depth or width convergence within the system. Further, the use of constant width and depth facilitates comparison with the subtidal water level model discussed below (Section 2.4). In the historical configuration, a $4 \mathrm{~m}$ deep channel transitions to a $6 \mathrm{~m}$ deep channel upstream of Rkm 28. Width is held constant at $1,500 \mathrm{~m}$. In the modern configuration, a $10 \mathrm{~m}$ deep channel seaward of Rkm 20 transitions to $8 \mathrm{~m}$ deep between Rkm 20-48. The width is somewhat wider near Jacksonville than the channelized coastal section (1,100 vs. $800 \mathrm{~m}$ ). Upstream (south) of Jacksonville, a long, shallow region (4 m depth, $4 \mathrm{~km}$ width, $85 \mathrm{~km}$ long) is modeled. A gradual transition to this wide channel is applied. A long, 100+ km narrow section that resembles the observed tidal river is included upstream of the shallow bay. The shallow upstream regions are required to allow the tide wave to decay toward zero, and to reproduce the observed tidal discharge, tidal prism, and tidal phases (see e.g., Wang et al., 2019). Due to channel streamlining, the modern planform is $4 \mathrm{~km}$ shorter than the historical planform (see Section 2.1).

A linearized, semi-analytical tide model is employed to gain insights into the reasons for tidal change. Schematized analytical models have often been used to explore how depth and other parameters affect tidal amplitudes (e.g., Jay, 1991; Friedrichs \& Aubrey, 1994; Winterwerp et al., 2013). Our analysis follows Dronkers (1964), makes the shallow-water approximation (wave length long compared to depth), and assumes 
that the tide wave amplitude $\eta$ is small relative to depth. Based on observations (see results), depth-averaged velocities are dominated by the $\mathrm{M}_{2}$ tide, to leading order; subtidal velocities are more than an order of magnitude smaller during typical conditions, and are neglected here. We set our coordinate system at the ocean boundary, and let $x$ be positive into the estuary. Assuming constant width $b$ and depth $h$, the depth and width integrated mass and momentum balance within a section are

$$
\begin{gathered}
\frac{\partial Q_{t}}{\partial x}+b \frac{\partial \eta}{\partial t}=0 \\
\frac{\partial Q_{t}}{\partial t}+r Q_{t}+g b h \frac{\partial \eta}{\partial x}=0
\end{gathered}
$$

where $Q_{t}$ is the tidal discharge, $g$ is gravity, and $r$ is the linearized frictional resistance. Under the assumption that tidal discharge is much larger than river discharge $\left(Q_{t} \gg Q_{r}\right)$, the linearized friction coefficient can be approximated (using the first term of a Fourier or Chebyshev expansion of $Q_{t}\left|Q_{t}\right|$; Dronkers, 1964) as

$$
r=\frac{8}{3 \pi} \frac{C_{d} Q_{T}}{b h^{2}}
$$

where $Q_{T}$ is the tidal discharge amplitude and $C_{d}$ is the drag coefficient. Following the solution procedure described in Dronkers (1964), a solution of the following form can be derived:

$$
\eta(x, t)=\operatorname{Re}\left[(\underbrace{A_{0} e^{k x}}_{\text {Reflected wave }}+\underbrace{B_{0} e^{-k x}}_{\text {Incident Wave }}) e^{i \omega t}\right],
$$

where $A_{0}$ and $B_{0}$ are constants for the reflected and incident wave components. The frequency $\omega$ is related to the tide period $T$ by $\omega=\frac{2 \pi}{T}$, and $k$ is a complex number described by

$$
k=\frac{\omega}{\sqrt{g h}}\left(-1+\frac{i r}{\omega}\right)^{1 / 2}
$$

An equation for tidal discharge $Q_{t}(x, t)$ then follows from the continuity equation (Equation 1 ). The solution for $\eta(x, t)$ and $Q_{t}(x, t)$ is found by applying boundary conditions. At the ocean boundary, we apply a sinusoidal wave at the $\mathrm{M}_{2}$ frequency $\left(T=12.42 \mathrm{~h}\right.$ ) with an amplitude of $\eta_{o}=0.7 \mathrm{~m}$. At the upstream boundary, a no-flux condition is applied. Following Dronkers (1964), we further subdivide the model into $N$ segments, each of $4 \mathrm{~km}$ length. For the internal boundaries between segments, the tidal discharge $Q_{t}(x, t)$ and water level $\eta(x, t)$ at the upstream boundary of each segment is matched to the downstream boundary condition of the next segment. This produces a system of $2 N$ equations which is solved through matrix inversion. The tidal amplitude $\eta$ and discharge $Q_{T}$ is solved iteratively. First, a solution is found using an initial estimate for $Q_{T}$. The friction term (Equation 3) is re-calculated using updated estimates of $Q_{T}$, and the equations resolved. The solution is iterated until it changes by less than $0.1 \%$ between successive approximations.

The model was calibrated by changing the value of the drag coefficient $C_{d}$ and comparing the solution with measured tidal amplitudes and discharge (see Results). To avoid coding errors, we also checked the model against the analytical solution of a constant width and depth configuration (Dronkers, 1964). Through calibration, the optimal drag coefficient for the historical and modern configuration was $C_{d}=0.007$ and $C_{d}=0.005$, respectively, within the range of 0.001-0.01 typically found for analytical models (Friedrichs $\&$ Madsen, 1992). The equivalent Manning's $n$ roughness coefficient is $0.031-0.033 \mathrm{~s} / \mathrm{m}^{1 / 3}$ (modern configuration) and $0.033-0.035 \mathrm{~s} / \mathrm{m}^{1 / 3}$ (historical configuration), using the conversion formula $n=R^{1 / 6}\left(\frac{C_{d}}{g}\right)^{1 / 2}$, where $R$ is the hydraulic radius (Area divided by wetted perimeter) and is approximately equal to $h$ in a wide channel. A root mean square error (RMSE) of 0.035 and $0.044 \mathrm{~m}$ was found between measurements and the modern and historical configurations, based on 5 and 8 measurements, respectively (see Results 
Table 1

Comparison of Measured and Modeled $M_{2}$ Tidal Statistics

\begin{tabular}{lccccc}
\hline & & $\begin{array}{c}\text { RMSE for tidal } \\
\text { amplitude (m) }\end{array}$ & $\begin{array}{c}\text { Tidal phase difference } \\
\text { (Jacksonville }- \\
\text { Mayport) (degrees) }\end{array}$ & $\begin{array}{c}\text { Relative phase between } \\
\text { tidal discharge and } \\
\text { amplitude (degrees) }\end{array}$ & $\begin{array}{c}\text { Tidal discharge } \\
\text { amplitude } \\
\left(\mathrm{m}^{3} / \mathrm{s}\right)\end{array}$ \\
\hline Modern & Measured & & 49 & 3 & 4,200 \\
& Delft 3D model & 0.008 & 41 & -8.6 & 4,130 \\
& Analytical model & 0.035 & 30 & 1.5 & 3,800 \\
\multirow{5}{*}{ Historical } & Measured & & 40 & Not known & 2050 \\
& Delft 3D model & 0.025 & 64 & 5 & 2400 \\
& Analytical model & 0.044 & 44 & -2 & 1,850 \\
\hline
\end{tabular}

The Root Mean Square Error is calculated between the measured and modeled M2 tidal amplitude at 5 locations (modern models) and 8 locations (historical models). Phases and discharges measured at Jacksonville. Water level phase is defined relative to the value in Mayport (Rkm 5.5). Relative phase is defined as $\varphi_{\mathrm{h}}-\varphi_{\mathrm{Q}}$, where $\varphi_{\mathrm{h}}$ and $\varphi_{\mathrm{Q}}$ are the phase angle of the vertical tide and cross-sectionally averaged discharge, respectively. Historical estimates of discharge amplitude are obtained from Rkm 30 (see Figure 6b).

and Table 1). Tidal discharge amplitudes for both configurations agreed with measurements to within $10 \%$, and the relative phase between discharge (velocity) and water level agreed well, to within $10^{\circ}$ (Table 1 ). The analytical model estimated a phase progression of $44^{\circ}$ and $30^{\circ}$ between Mayport and Jacksonville for the historical and modern configuration; the equivalent based on available measurements was $40^{\circ}$ and $49^{\circ}$.

\subsection{Subtidal Water Level from River Discharge}

We next develop an analytical model that describes how the tidally averaged (subtidal) water surface is influenced by geometry changes. The same geometry as in the tidal model (Section 2.3) is considered. As shown by Godin (1999), the effective subtidal friction is set by river flow, tidal forcing, and non-linear interaction between both (see also Kukulka \& Jay, 2003a). Because average river discharge $\left(200 \mathrm{~m}^{3} / \mathrm{s}\right)$ is small compared to the typical $\mathrm{M}_{2}$ tidal discharge $\left(\sim 4,200 \mathrm{~m}^{3} / \mathrm{s}\right)$, we follow Buschman et al. (2009) and Godin (1999) and examine the parameter space in which tidal currents outweigh river flow currents. We also assume that bed slope effects and the effect of surface slope on water depth are negligible. Data show that subtidal water level variations in the estuary region are small relative to mean depth under normal conditions, justifying this assumption (see also Henrie \& Valle-Levinson, 2014). A more thorough treatment of bed and river slope effects, particular in tidal rivers, is presented in Kästner et al. (2019).

For a constant width segment of an estuary, the tidally and sectionally averaged momentum balance becomes a balance between the barotropic pressure gradient and tidally averaged bed stress (e.g., Buschmann et al., 2009; Kukulka \& Jay, 2003b):

$$
g h \frac{\partial z_{r}}{\partial x}=\frac{-T_{r}}{\rho}
$$

where the bed stress is $T_{r}$, the density of water is $\rho$, the tidally averaged surface slope relative to a fixed datum is $\frac{\partial z_{r}}{\partial x}$, and the brackets denote a tidal average. For simplicity, we neglect small tributaries and the subtidal discharge caused by the correlation between vertical and horizontal tidal velocities (Stokes transport). Equation 6 is simplified by using the definition for bed stress, $T_{r}=\rho C_{d}|U| U$, where $U$ is the velocity, $C_{d}$ is the drag coefficient, angle brackets denote an average over the tide and the absolute value preserves the directionality of stress within the brackets. The velocity $U$ consists of tidal fluctuations and river flow, that is, $U=U_{T} \cos (\omega t)+U_{r}$, where $U_{r}$ is negative because discharge moves in the minus $x$ direction. Following Dronkers (1964), we apply a Chebyschev polynomial expansion on the velocity term $|U| U$. We then tidally 
average the expansion term and retain only components that are significant (see Kukulka and Jay (2003b) and Buschman et al. (2009). The tidally averaged bed stress is then approximated as:

$$
\frac{T_{r}}{\rho}=\frac{-C_{d}}{\pi}\left(p_{1} U_{o} U_{R}+\frac{3}{2} p_{3} U_{R} U_{o}\left(\frac{U_{T}}{U_{o}}\right)^{2}\right),
$$

where $p_{1}=16 / 15$ and $p_{3}=32 / 15$ are expansion coefficients, and $U_{o}$ is a velocity scale. We have defined the positive river velocity scale $U_{R}=-U_{r}$; the minus sign in Equation 7 accounts for the fact that river discharge moves in the minus $x$ direction. We follow Buschman et al. (2009) and set the velocity scale $U_{o}$ to the absolute value of the maximum velocity. Applying the simplifications discussed above, we find that the differential equation for $\frac{\partial z_{r}}{\partial x}$ can be approximated as:

$$
\frac{\partial z_{r}}{\partial x}=1.36 \frac{C_{d} Q_{R} U_{T}}{g b h^{2}},
$$

where $Q_{R}=b h U_{R}$ is the river discharge. More generally, since $p_{1}$ and $p_{3}$ change slightly as the ratio of river to tidal discharge varies (e.g., due to spring-neap cycle), we state that, to first order, $\frac{\partial z_{r}}{\partial x} \sim \frac{C_{d} Q_{R} U_{T}}{g b h^{2}}$. A similar, more complex analysis of the subtidal slope that includes additional tidal bands is found in Buschman et al., 2009.

The analytical development in Equations 6-8 is applied to the geometry of our model (Figures 2-4) by requiring water level at the boundary of each constant width/depth segment (of $4 \mathrm{~km}$ length) to match the next. We integrate Equation 8 under the assumption that the bed slope is negligible and that river discharge, tidal velocity, width, and depth are approximately constant over the $4 \mathrm{~km}$ segment under consideration. This yields

$$
z_{r}(x)=\alpha x+z_{r i}
$$

where $\alpha=1.36 \frac{C_{d} Q_{R} U_{T}}{g b h^{2}}$ is the subtidal river slope and the constant of integration $z_{r i}$ is the mean water level at the downstream boundary of segment $i$. At the ocean $(x=0)$, sea-level is used as a boundary condition. For consistency, the subtidal model uses the drag coefficients $C_{d}$ that were calibrated from the historical and modern analytical tidal model $\left(C_{d}=0.007\right.$ and $\left.C_{d}=0.005\right)$.

\subsection{Delft-3D Numerical Model}

To assess the storm tide produced by hurricane Irma under historic and modern channel conditions, we run simulations using the Delft3D numerical model (Deltares, 2014). Such a model is better suited for modeling unsteady, energetic storm conditions than the simplified analytical models described above, and better represents system depth. Two configurations were developed, one using a grid based on 1898 bathymetry (see section 2.1), and another based on modern bathymetry from 2014 (Figure 1). The domain stretches from the coastal ocean to a location $100 \mathrm{~km}$ upstream of Jacksonville (see Figures 1a) and is divided into two domains (labeled $A$ and $B$ in Figure 1). The river upstream of Jacksonville (Domain B) is approximated as a long, wide and shallow bay to allow the observed damping of the tidal wave. The width is $4,000 \mathrm{~m}$ and the depth is approximated to be $4 \mathrm{~m}$ deep. Bathymetry is not adjusted for sea-level rise. The model contained 545,500 grid cells, with the majority $(\sim 97 \%)$ in Domain A between the ocean boundary and Jacksonville. A grid resolution of $30 \mathrm{~m}$ was applied within the shipping channel.

For calibration, the model is run for 40 days using average river discharge $\left(200 \mathrm{~m}^{3} / \mathrm{s}\right)$. Tidal forcing at the boundary is obtained from the NOAA gauge at Mayport and is scaled by a factor of 1.06 to account for the attenuation of tides through the jetties. A different Manning's friction coefficient is applied to vegetated and unvegetated parts of the domain, following observations in similar modeling efforts (Bacopoulos et al., 2012). Following Bacopoulos et al. (2009), Bacopoulos, Tang, et al. 2017, we run the model in depth-averaged mode, since the estuary is likely to be well-mixed during highly energetic storm conditions. 
In other estuaries, neglecting density variations can produce a small (generally $<10 \%$ ) underestimation in storm tide amplitudes (e.g., Orton et al., 2012); here, we assess the validity of our approach through comparison with measurements.

We calibrate the model to reproduce the observed tidal statistics between the estuary inlet and Jacksonville (see Results, Table 1). The optimal Manning's $n$ coefficient for the historical channel and wetland was $n=0.025 \mathrm{~s} / \mathrm{m}^{1 / 3}$ and $n=0.05 \mathrm{~s} / \mathrm{m}^{1 / 3}$, and for the modern configuration was $n=0.02 \mathrm{~s} / \mathrm{m}^{1 / 3}$ and $n=0.04 \mathrm{~s} /$ $\mathrm{m}^{1 / 3}$. Within Domain B, a constant $n=0.025 \mathrm{~s} / \mathrm{m}^{1 / 3}$ is used for both configurations. Simulations agree well, overall, with available measurements. Simulated tidal discharge agrees to within $2 \%$ and $15 \%$ with modern and historical measurements (Table 1), likely within the uncertainty of measurements. Modern simulations and measurements both depict a progressive wave which takes about $1.5 \mathrm{~h}$ to travel from Mayport and Jacksonville, with minor differences in phase progression $\left(8^{\circ}\right)$ and relative phase of water level and tidal discharge $\left(<12^{\circ}\right)$. A somewhat larger difference is observed in the simulated historical progression of the $\mathrm{M}_{2}$ wave $\left(24^{\circ}\right)$, likely in large part because of uncertainty in the empirical estimate (which was estimated from the mean tabulated travel time).

Tidal amplitudes are well calibrated in both simulations (Table 1). The root-mean-square error (RMSE) in the $\mathrm{M}_{2}$ constituent was $0.025 \mathrm{~m}$ (8 measurements) and $0.008 \mathrm{~m}$ (5 measurements) for the historical and modern configurations, respectively. The slightly larger Manning coefficient historically may reflect larger sub-gridscale roughness (e.g., sand dunes and other bathymetric variation), or may account for uncertainty in the historical bathymetric measurements. Conversely, salinity stratification within the modern system (e.g., Bacopoulos, Kubatko, et al., 2017; Bellino \& Spechler, 2013) may also reduce the effective, depth-averaged frictional effect, as has also been observed at other locations (Giese \& Jay, 1989). The RMSE in the historical configuration only increases to $0.036 \mathrm{~m}$ from $0.025 \mathrm{~m}$ when the Manning's $\mathrm{n}$ is decreased from $n=0.025 \mathrm{~s} / \mathrm{m}^{1 / 3}$ to $n=0.02 \mathrm{~s} / \mathrm{m}^{1 / 3}$ (see also Figures below). Therefore, changes to the friction coefficient exert only a minor influence on tidal results.

To simulate hurricane Irma effects on water level, we apply the known water-level variations during the storm at the ocean boundary (approximately $10 \mathrm{~km}$ from the estuary inlet; see Figure 1), using data from near the estuary entrance (tide gauge at Mayport). Data are scaled up by $6 \%$ to account for the decay in tides between the boundary and the tide gauge. A similar 'storm surge hydrograph' approach is used in other studies (e.g., Xu \& Huang, 2014). Fluvial discharge effects during Irma are modeled using two approaches. First, we run the storm surge model by applying a constant discharge of $0-7,000 \mathrm{~m}^{3} / \mathrm{s}$ at the upstream boundary, in increments of 1,000 or $2,000 \mathrm{~m}^{3} / \mathrm{s}$. This enables us to estimate the sensitivity of peak water level to discharge. Additionally, we also model the discharge measured at USGS station \#02246500 in Jacksonville using a "virtual" boundary condition (Deltares, 2014) This virtual boundary condition forces the model to reproduce the total discharge measured at Jacksonville (tides + surge + discharge) by applying either a source or sink discharge at the gauge location (as needed). We found this approach greatly improves comparison of the model to measured water levels, compared to using the USGS "tidally filtered" discharge product at the model boundary. The virtual boundary approach is needed because the measured discharge includes storm surge currents and the effects of local winds, which cannot easily be separated from local run-off. Accounting for such factors requires hydro-meteorological modeling (e.g., as done in Bacopoulos, Tang, et al., 2017), and is beyond the scope of the current effort. Since the virtual boundary approach likely introduces some uncertainty into the historical discharge forcing, we compare results with the constant discharge simulations; as shown in the results, the different approaches yield broadly consistent results.

The individual effects of tides, storm surge, and local discharge effects on water levels are decomposed by running 40days "tide-only," "tide + surge," and "tide + surge + discharge" model runs. The differences between these model runs are used to evaluate individual contributions to the total water level. For example, surge effects are estimated by subtracting "tide-only" results from the "tide + surge" results, and discharge effects are estimated by subtracting the "tide + surge" model results from the "tide + surge ++ discharge" model results. This approach, though commonly used (e.g., Shen et al., 2006), does not account for the modification of the tidal phase speed by the surge, or nonlinear frictional interaction (see e.g., Familkhalili et al., 2020; Horsburgh \& Wilson, 2007; Valle-Levinson et al., 2013). Hence, some tidal energy is likely aliased into our estimated surge signal, and some tidal and surge effects are aliased into our local discharge estimate. For this reason, it is important to check that numerical simulation results are consistent with 

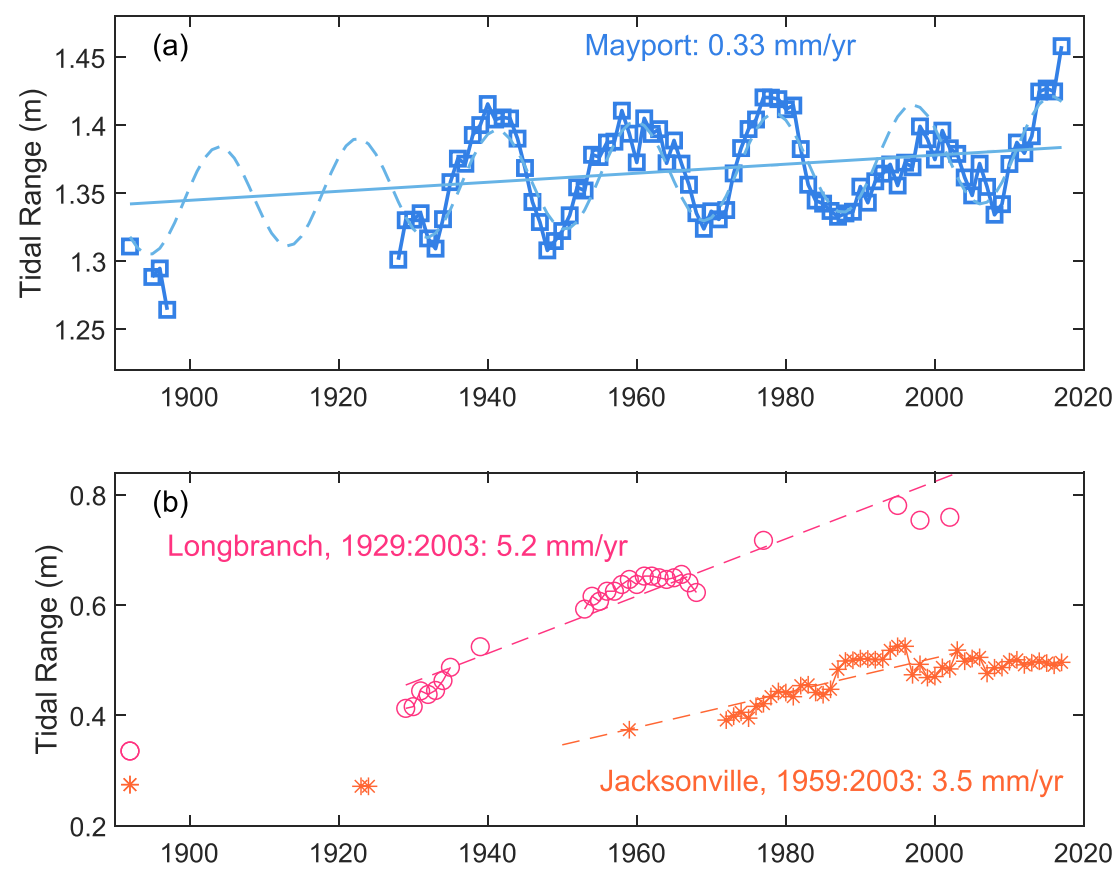

Figure 5. Changes in annual mean tidal range since the 1890s at (a) Mayport ( River km 5.5) and (b) JacksonvilleLongbranch (River $\mathrm{km} \mathrm{31}$, violet color) and downtown Jacksonville (River $\mathrm{km} \mathrm{40,} \mathrm{orange} \mathrm{color).} \mathrm{Trends} \mathrm{were}$ obtained using robust linear regression and had a standard error of $0.06 \mathrm{~mm} / \mathrm{yr}$. (Mayport), $0.3 \mathrm{~mm} / \mathrm{yr}$ (JacksonvilleLongbranch) and $0.4 \mathrm{~mm} / \mathrm{yr}$ (Jacksonville).

available empirical records and that trends are consistent with analytical and numerical model results obtained during low-discharge conditions.

\section{Results}

We next use our data, analytical modeling, and numerical simulations to explore how tidal dynamics and the river slope in the Saint Johns River Estuary have shifted during typical discharge conditions (Section 3.1 and 3.2). After discussing measurements during hurricane Irma (Section 3.3), we use numerical simulations to explore how anthropogenic modifications may have altered water levels during hurricane Irma (Section 3.4). Reasons for changes are explored in the Discussion.

\subsection{Tide Changes}

Water level observations depict a continually evolving tidal range over the past century (Figures 5 and 6).

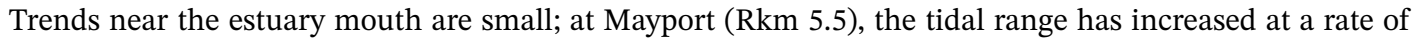
$\sim 0.33 \mathrm{~mm} / \mathrm{yr}$. since 1892, for a total increase of $0.04 \mathrm{~m}$ (Figure 5a), and the $\mathrm{M}_{2}$ amplitude (Figure 6a) has increased from 0.63 to $0.67 \mathrm{~m}$. By contrast, tidal range from Dames Point ( $\mathrm{kkm} \mathrm{17.3)}$ to the end of the maintained shipping channel ( $\sim \mathrm{Rkm} 38$ ) has more than doubled (Figure 7$)$. At Longbranch (Rkm 31; open circles), tidal range increased from 0.33 to $0.77 \mathrm{~m}$ since 1900, at an average rate of $5.2 \mathrm{~mm} / \mathrm{yr}$ between 1929 and 2003; in downtown Jacksonville (orange stars), tidal range increased from about 0.29 to $0.55 \mathrm{~m}$ over the same period, an increase of $\sim 90 \%$ (Figures $5 \mathrm{~b}$ and 7 ). The divergence in trends between stations near the coast and inland stations points to a local cause, rather than far field changes in the Atlantic Ocean.

The observed tidal amplitude changes are reproduced by both the analytical and numerical models (Figure $6 \mathrm{a}$, Table 1). The maximal tide change occurs within the mid-estuary, roughly between Rkm 20-30 (Figures 6a and 7). The magnitude of increase becomes less pronounced further upstream (Figure 6a), even though the percentage increase is still large (Figure 7). Both modeling and measurements suggest that the tidal discharge amplitude approximately doubled since the 1890s (Figure 6b). The tides have retained 

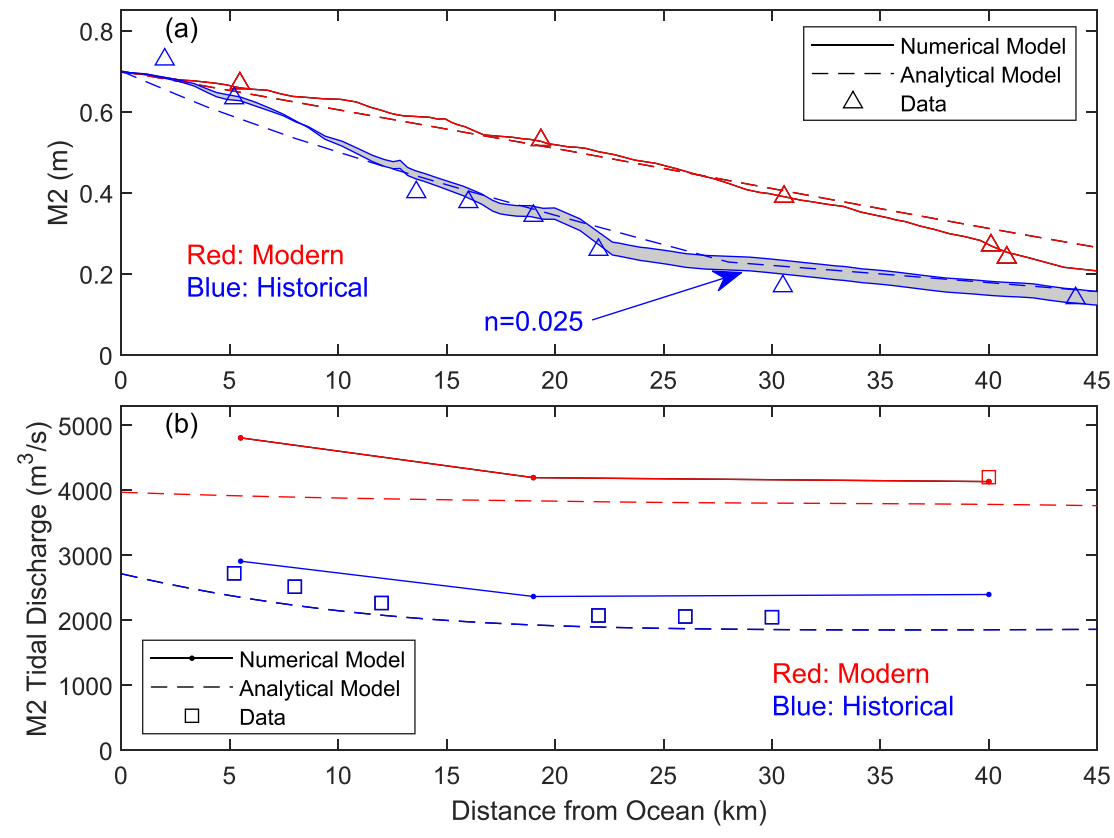

Figure 6. Comparison of historical and modern $\mathrm{M}_{2}$ amplitude (a) and $\mathrm{M}_{2}$ tidal discharge (b). In (a), the gray shading bounds the numerically modeled tidal amplitudes that occur for a Manning's n value of $0.025 \mathrm{~s} / \mathrm{m}^{1 / 3}$ (bottom line) versus $n=0.02 \mathrm{~s} / \mathrm{m}^{1 / 3}$ (top line). Historical tidal and discharge estimates are obtained primarily from Gieseler (1893), with a few additional tidal amplitudes obtained from archival Coast and Geodetic Survey records (see Supplemental Information).

their progressive wave characteristic, with tidal flow nearly in phase with water level (Table 1). The phase progression of the tide wave is about the same; Gieseler (1893) reports that the tide wave took slightly less than $1.5 \mathrm{~h}$ to propagate between Mayport and Jacksonville. The time today is $\sim 1.7 \mathrm{~h}$.

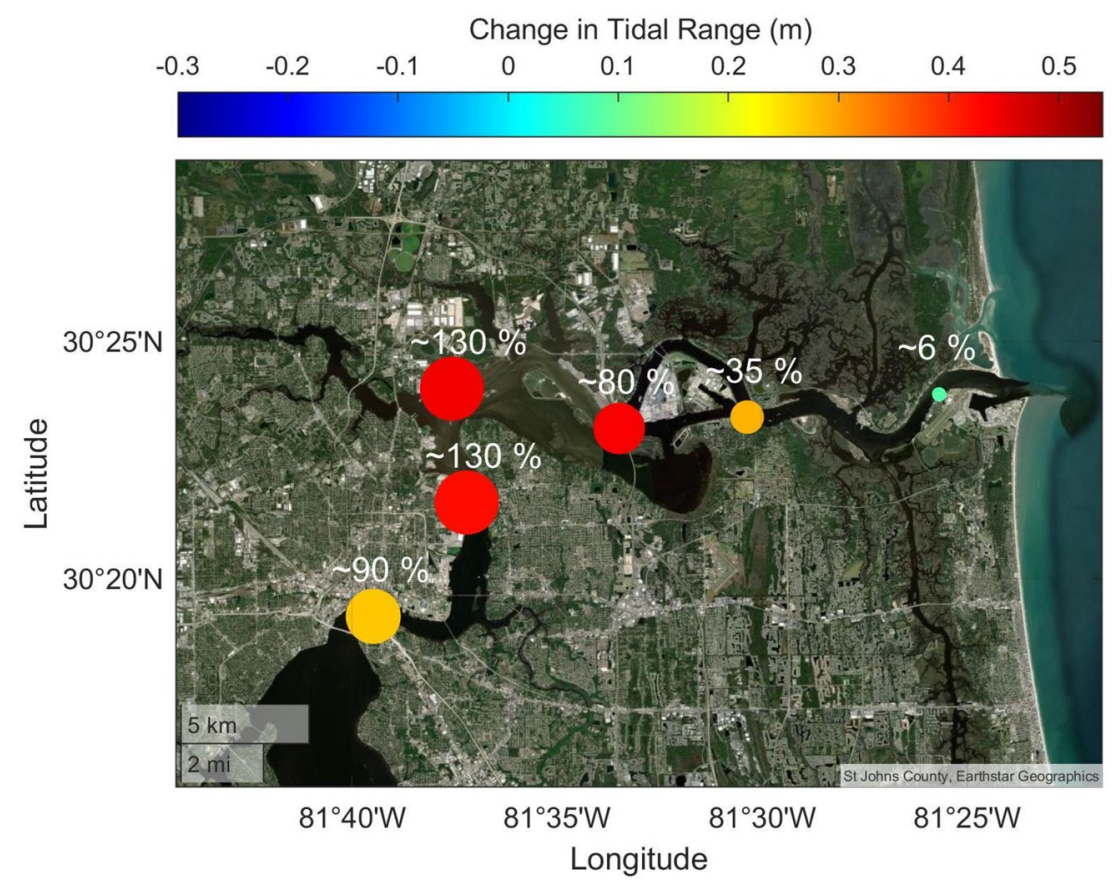

Figure 7. The spatial change in tidal range, based on modern minus historical values (see Figure 6). The size of each bubble is proportional to the total change. The percent increase relative to historical conditions is indicated. 


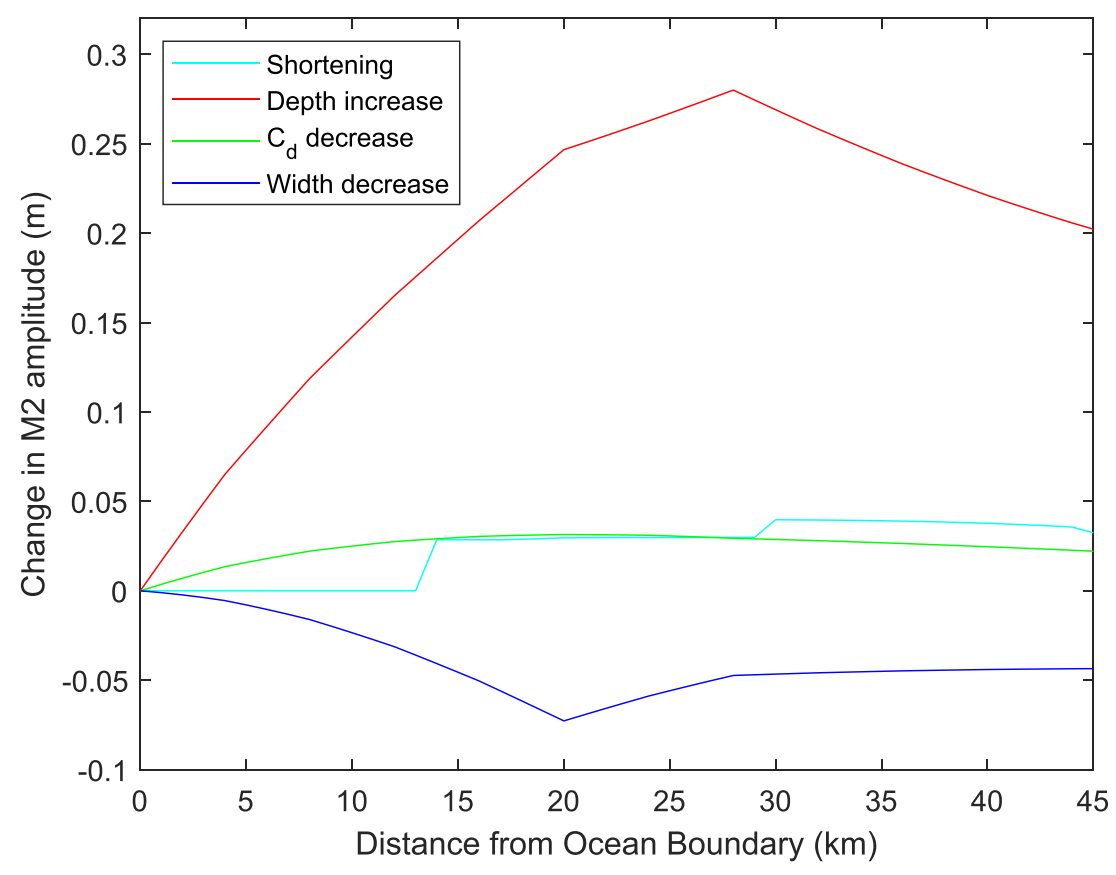

Figure 8. Causes of tidal change, estimated using the analytical tide model. Results obtained using the modern configuration, changing one parameter at a time. Results show how much tidal amplitude would change if one component was changed from the historical value to the modern value. For example, increasing depths from the historical to the modern value (see Figure 3) would produce a maximum increase of nearly $0.28 \mathrm{~m}$ in tidal amplitude.

The reasons for tidal changes are explored by applying sensitivity tests to the analytical model (Figure 8). Keeping all other parameters equal, we find that increasing the depth produces the largest increase in tidal statistics. The change is spatially variable, with a peak value of nearly $0.28 \mathrm{~m}$ found between $\mathrm{Rkm} 25$ to $\mathrm{Rkm}$ 30. Both the decrease in the drag coefficient and channel length changes produce minor (less than $+0.05 \mathrm{~m}$ ) changes in tidal range, consistent with numerical modeling results (Figure 6). Shortening effects are cumulative and most prominent near Jacksonville. Decreasing channel width reduces tidal amplitudes, all other parameters held equal. The maximum decrease of slightly more than $0.05 \mathrm{~m}$ is found around Rkm 20 , and may be caused by the increase in tidal currents (and therefore friction factor $r$ ) that occurs when width is decreased. Depth and the drag coefficient both influence tidal amplitudes by altering the friction factor (Equation 3); since the percentage depth increase is much bigger than the drag coefficient decrease, its observed influence is larger (Figure 8; see also discussion).

\subsection{Mean Water Level Changes}

Archival records show that sea-level is rising both at the estuary inlet and in Jacksonville (Figure 9). At Mayport, sea level has increased at an average rate of $2.5 \mathrm{~mm} / \mathrm{yr}$ (Figure 9a) since 1895, slightly larger than the $2.1 \mathrm{~mm} / \mathrm{yr}$. registered $35 \mathrm{~km}$ northwards in Fernandina (see Figure 1 for location). During the 20th century, a smaller sea-level rise rate is observed in Jacksonville, compared to Mayport. The difference between the two locations between 1929 and 1995 was $\sim 1.5 \pm 0.3 \mathrm{~mm} / \mathrm{yr}$ (Figure 9b). More recently, differences in sea-level rise trends have stopped or even reversed. Between 1995 and 2017, rates were slightly larger in Jacksonville than Mayport $(4.2 \pm 1.5 \mathrm{~mm} / \mathrm{yr}$. vs. $3.7 \pm 1.3 \mathrm{~mm} / \mathrm{yr})$, though results are not statistically different. Sea-level rise variations may in part reflect differences in subsidence; vertical land motion rates in the northeastern Florida region are -1 to $-2 \mathrm{~mm} / \mathrm{yr}$, with considerable variability and uncertainty due to short GPS/GNSS record lengths (Blewitt et al., 2018).

The differences in the sea-level rise in Jacksonville and the estuary mouth region during the 20th century may also in part be driven by a reduction in the average surface slope in water level caused by channel deepening (Equation 8; Figure 10). We isolate the effect of river discharge by first removing oceanic variability, by subtracting the monthly averaged water level measured in Mayport from all gauge series. Next, 

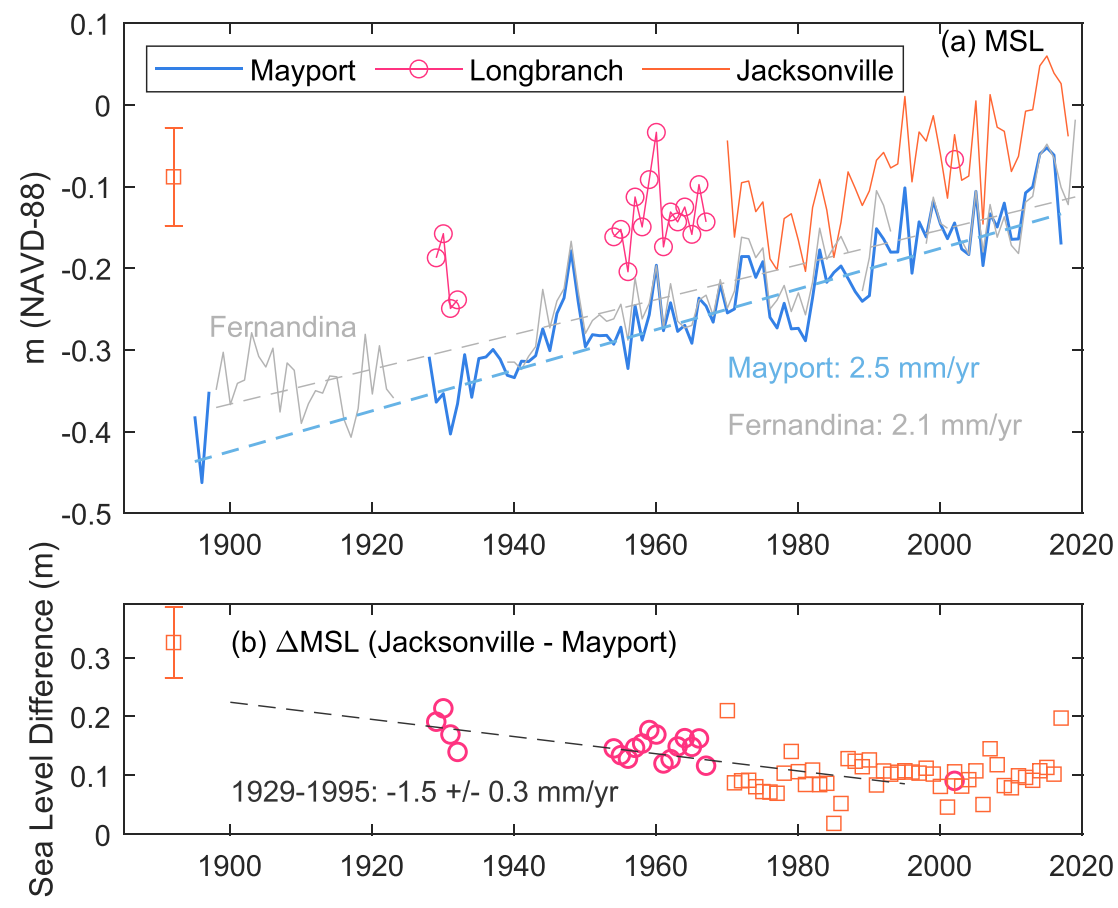

Figure 9. (a) Comparison of annually averaged mean sea level at Mayport (coastal station) and at Longbranch (eastern Jacksonville, Rkm 30) and downtown Jacksonville ( Rkm 40) (b) Since the 1890s, the annual difference in mean sea level between Jacksonville and Mayport ( $\Delta$ MSL) decreased. In (a), a difference in sea-level rise of $\sim 0.4 \mathrm{~mm} / \mathrm{yr}$. is found between the gauges at Mayport and Fernandina (gray line), located $30 \mathrm{~km}$ north.

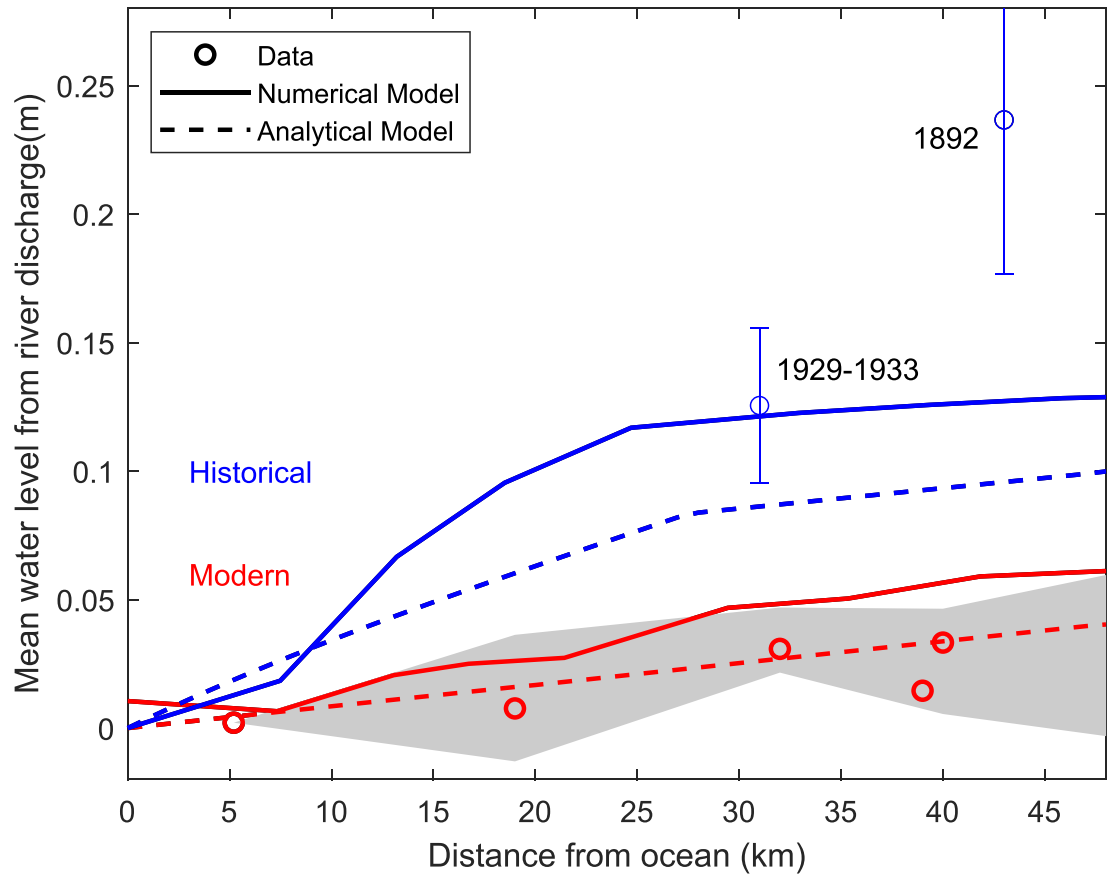

Figure 10. Comparison of modeled and measured mean water level caused by river discharge, for both historical (blue) and modern (red) conditions. Data are based on the difference between monthly averaged water level between a gauge location and the monthly water level in Mayport ( $\mathrm{kkm}$ 5.5). For each location, some residual difference in water level occurred at zero discharge in modern measurements; this offset was removed from both modern and historical measurements. The shaded region depicts the 10th and 90th percentile of measurements. 
the super-elevation caused by river discharge is obtained by comparing mean water levels during average discharge $\left(200 \mathrm{~m}^{3} / \mathrm{s}\right)$ with those during periods of no net discharge. A measureable vertical offset was found between Mayport and upstream stations under conditions of zero discharge (see supplemental information); for consistency, this offset was removed from all data in Figure 10, including those for which no discharge measurements are available.

The measured and modeled rise in mean water level caused by average river discharge is small, particularly under modern conditions (Figure 10). Semi-analytical and numerical model results agree reasonably well with each other, and suggest an approximate halving of the water level rise caused by average river flow between historical and modern configurations (order 0.05-0.07 $\mathrm{m}$ decrease in water level in Jacksonville since 1900, relative to Mayport). Modern data is consistent with the semi-analytical model, and shows an approximately linear rise between the ocean and Jacksonville, to within data accuracy; the numerical model results show a slightly larger rise. Historical measurements from 1929 to 1932 are consistent with the historical model result, while the more uncertain data from 1892 is biased high. Most of the modeled change in fluvial effects between historical (blue) and modern (red) curves occurred near the ocean, seaward of Rkm 25-30; this is also where the largest increases in depth occurred (Figure 3). Upstream of Rkm 25-30, the increase in average depth is less, likely leading to a smaller change in river slope (Equation 8). The doubling of tidal discharge (Figure 6b) through this section also tends to counteract the effect of depth increases (Equation 8).

Both measurement and modeling limitations likely influence results in Figure 10. For example, both the numerical and analytical model neglect sources of mean discharge below Jacksonville. Also, the analytical model does not consider the Stokes drift compensation flow caused by the correlation of horizontal and vertical tidal motions (see Moftakhari et al., 2016 for a definition; this discharge is estimated to be $\sim 25 \%$ of the mean flow in Jacksonville, based off of measurements). Other assumptions-such as the assumption of zero bed slope-could make a slight difference in the analytical model results. Further, neither the numerical or analytical model include wind effects or the mean slope caused by salinity intrusion. Many sources of precision and bias error add uncertainty to the measurements as well. The large variability around the mean, shown by the gray shading in Figure 10, shows that many processes-from wind to discharge-drive month-to-month variability. In Jacksonville, average water levels less than $1 \mathrm{~km}$ from each other differ by 0.01-0.02 m (Figure 10). The reasons are unclear, but could include leveling error, benchmark or datum drift, differences in subsidence, or real differences in water level, for example, transverse water surface slope. Nonetheless, both measurements and models support the inference that channel deepening has reduced the response of mean water level to increases in discharge.

\subsection{Measurements During Hurricane Irma}

During hurricane Irma (September 10 to 12, 2017), the maximum total water level (TWL) at both Mayport and Jacksonville (NOAA gauge) reached $1.7 \mathrm{~m}$ relative to the NAVD-88 datum. However, the timing of the peak and the hydrodynamic factors contributing to the water level were different. At the estuary inlet, measured water level peaked slightly more than $2 \mathrm{~h}$ after the predicted high tide of $0.64 \mathrm{~m}$ (Figure 11). By contrast, peak water levels in Jacksonville occurred on the following high tide. At Jacksonville, waters stayed within $0.05 \mathrm{~m}$ of peak TWL for $2.5 \mathrm{~h}$ (Figures 11a), with the long duration likely contributing to the severity of flooding. At Mayport, water levels only briefly attained a peak and remained above $1.5 \mathrm{~m}$ for less than an hour.

We estimate that the predicted tide at Jacksonville during hurricane Irma was $\sim 0.13 \mathrm{~m}$ larger today than it would have been under historical conditions, given the approximately $90 \%$ increase in tidal range there (Figure 7). Hence, tides likely played a larger role in the total water level during Irma than they would have a century ago. Fortuitously, a worst case scenario-amplified tides occurring in phase with storm surgewas avoided. At the coast, storm surge (measured-predicted water level) peaked approximately half an hour before the predicted low tide (Figure 11). A similar timing occurred in Jacksonville. Hence, as the tide was rising in Jacksonville, the storm surge was falling, counteracting each other (Figure 11).

The long time scale of flooding at Jacksonville occurred because of the combined effect of storm surge, local discharge, and the astronomical tide. The local discharge wave peaked approximately 1 day after peak flood waters (Figures 11d); hence, the rising arm of the discharge hydrograph added significantly to the observed 

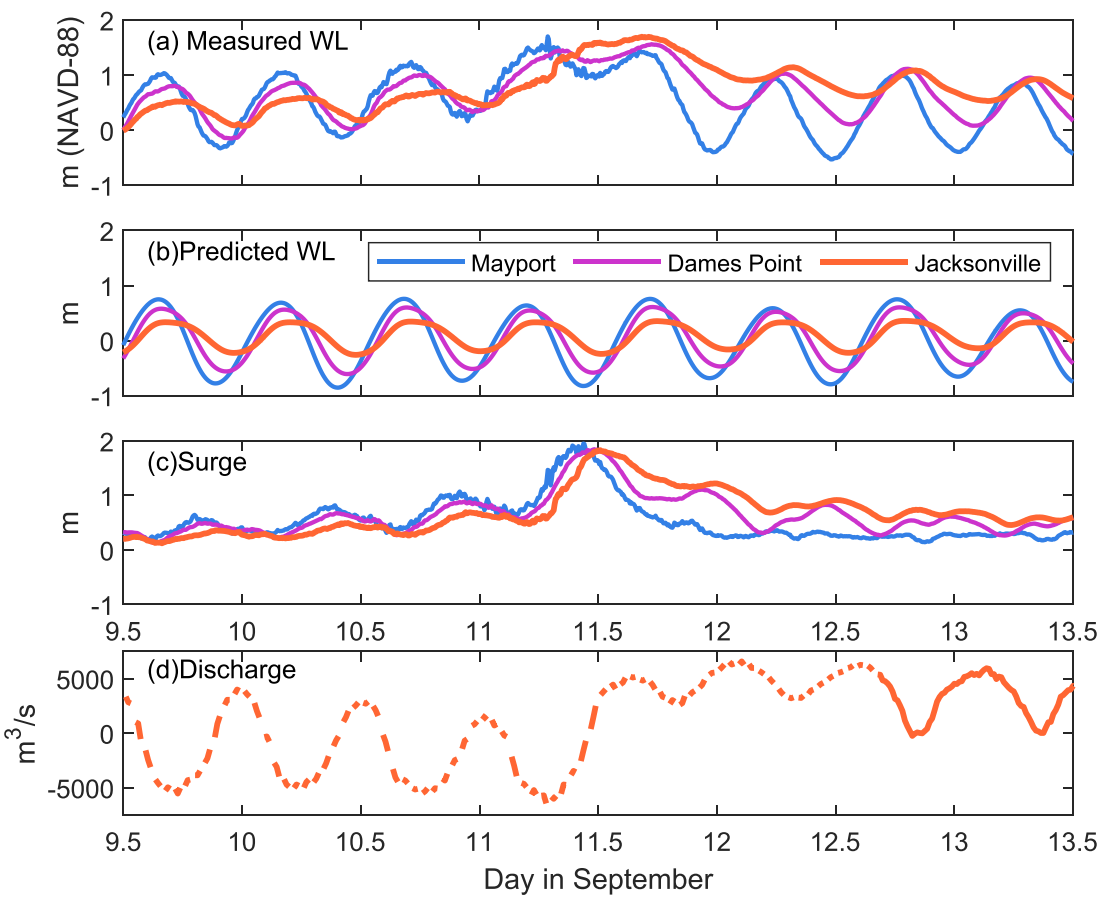

Figure 11. Water Level and Discharge in the Saint Johns River Estuary in September 2017. (a) Measured Water Levels; (b) Predicted tidal water levels (from NOAA); (c) The difference between measured and predicted water levels, or surge; (d) the measured discharge in Jacksonville (blank spaces denote recording gaps). Data are from Mayport (Rkm 5.5; blue), Dames Point ( Rkm 19; purple) and Jacksonville (Rkm 40; orange); see legend in (b).

peak water level. The large precipitation of 0.18 to $0.28 \mathrm{~m}$ within Jacksonville (Cangialosi et al., 2018) likely influenced the local discharge. Another factor was the southerly (south-to-north) wind in the eastern quadrant of hurricane Irma as it moved north thru the western portion of Florida (domain B in Figure 1; see also Bacopolous et al., 2009; 2017 for investigation of local wind effects). This likely produced significant local wind setup near Jacksonville at or near the same time that marine-sourced surge was peaking. As the rising arm of the discharge freshet meets the storm surge and tide, a surface water level difference develops between the coast and Jacksonville (Figure 11a). Due to the larger channel depths and lower frictional resistance today, a smaller water-level slope may have been required to drain this water today, than historically. We next investigate this idea by evaluating simulations of hurricane Irma.

\subsection{Simulations of Hurricane Irma: Historical Versus Modern}

Simulations show that both maximum tidal amplitudes and maximum storm surge during hurricane Irma increased everywhere due to channel reconfiguration and deepening, relative to what they would have been in 1898 (Figures 12a and 12b). The increase in both tidal amplitude and storm surge amplitude is spatially variable, rising from zero (no change) at the coast to a maximum increase at Rkm 23-25 near Dames Point of $\sim 0.16$ and $\sim 0.57 \mathrm{~m}$, respectively (Figures 12a and 12b). Similar to tides (Figures 6, 7, and 12a), the difference between modern and historical surge diminishes further upstream (Figure 12b). As discussed above (Section 3.3), these peak tidal and surge amplitudes were not phased together, diminishing their combined effect.

In contrast to tides and surge, the simulated super-elevation in water level caused by peak flood discharge (about 1 day after peak water level) decreases significantly between the historical (blue line) and modern configurations (red line, Figure 12c). The difference between historical and modern water levels expands from zero near the inlet to $\sim 0.6$ m near Dames Point ( $\mathrm{kkm} 23-25$ ), and remains fairly constant upstream to Jacksonville (Figure 12c). 
a)

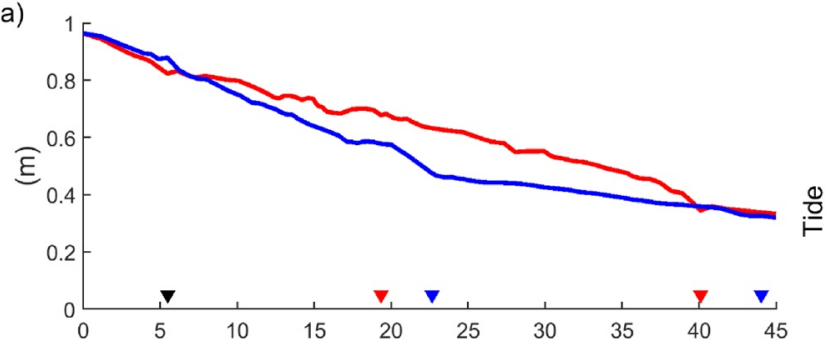

b)

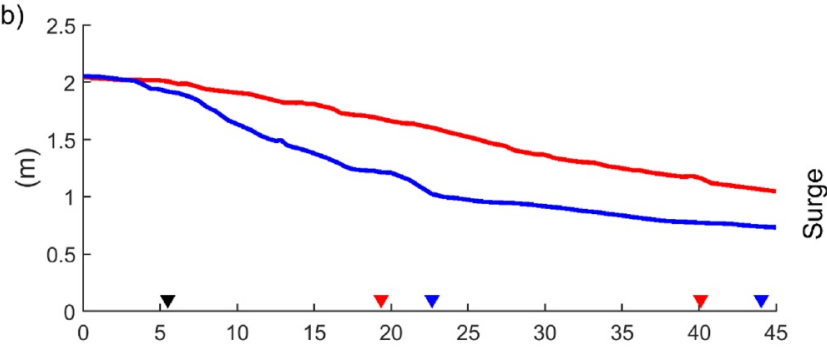

c)

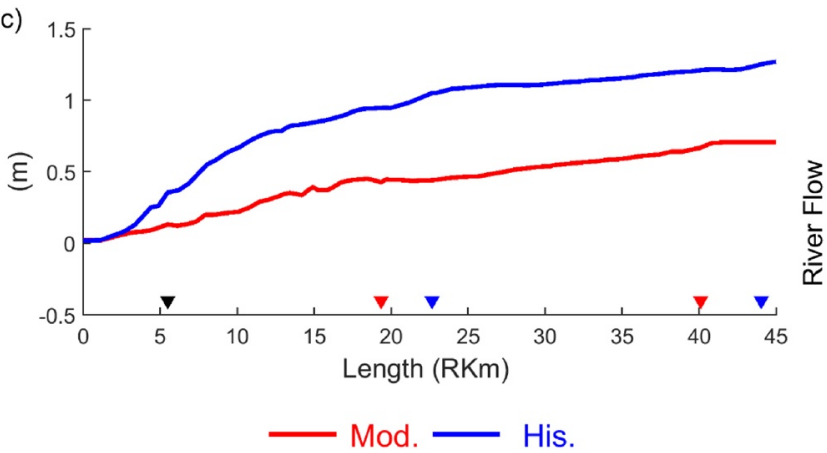

Figure 12. Simulated peak amplitude of (a) tides; (b) storm surge and (c) river flow effects during hurricane Irma. These peaks occurred at different times and did not coincide with the overall maximum water level. Coloring denotes the modern configuration (red) and historical configuration (blue). Datum is the still water level in the ocean domain.
At its peak, total water level (tide + surge + river flow) was simulated to be up to $0.2 \mathrm{~m}$ larger in the historical configuration, except at the estuary inlet (Figure 13). There, peak water levels were driven primarily by storm surge, and occurred $\sim 10 \mathrm{~h}$ earlier than upstream (Figure 13a; see also Figure 11). Individually, the contributions of tide, surge, and river discharge (Figures 13b, 13c, and 13d) to the peak total water level (Figure 13a) are similar to Figure 12, just of smaller magnitude. Because the maximum river flow, surge and tidal amplitudes occurred at different times, the worst-case scenario was avoided (compare Figures 12 and 13). Overall, the modeled peak water level agrees well with measurements (red-dots in Figure 13a), except for the anomalously low USGS measurement in Jacksonville.

Overall, the increase in marine-sourced water levels (tides + surge) in the modern model is counteracted by a decrease in fluvial (river discharge) water levels (Figures 13 and 14). Changes in both factors are small near the estuary inlet, but increase rapidly inland. The modeled increase in tides + surge is maximal in mid-estuary, and diminishes further upstream (Figure 14). By contrast, fluvial differences persist. Hence, the largest modeled decrease in peak water level $(\sim 0.2 \mathrm{~m})$ from the historical configuration was simulated in Jacksonville; effectively, the sum of tide + surge effects $(+0.25 \mathrm{~m})$ is less than river discharge effects $(-0.45 \mathrm{~m}$; Figure 14). Based on Figure 13, approximately $10 \%$ of the decreased total water level in Jacksonville is attributable to the $\sim 4 \mathrm{~km}$ shortening in channel length to the ocean. The remainder is attributable to changes in depth, width, and drag coefficient. Overall, storm surge and tides contribute $\sim 2 / 3$ to modern peak water levels, compared to $\sim$ half under historical bathymetry.

Model sensitivity tests show that results remain qualitatively similar when the river discharge condition or the drag coefficient are altered (Figure 15). In these simulations, we leave oceanic forcing unchanged, but replace the virtual discharge condition with a constant river discharge (see Section 2.5). Results suggest that for any fluvial discharge greater than $\sim 2,600 \mathrm{~m}^{3} / \mathrm{s}$, the maximum water level in Jacksonville would have been higher, historically, than today (Figure 15). For lesser discharge, the situation is reversed due to the effect of increased tides and storm surge. A simulated constant discharge of $3,500 \mathrm{~m}^{3} / \mathrm{s}$ and $6,000 \mathrm{~m}^{3} / \mathrm{s}$ produces modern water levels that are consistent with USGS $(1.54 \mathrm{~m})$ and NOAA $(1.69 \mathrm{~m})$ peak measurements, respectively. Within this discharge range, simulated water levels in the historical configuration exceed modern levels, as in Figure 13. Because results in Figures 13 and 15 are consistent, we surmise that the uncertainty involved in applying the modern discharge measurement as a virtual boundary condition in the historical configuration does not shift overall conclusions. Similarly, changing the Manning coefficient in the historical simulation modifies, but does not change, conclusions (see Figure 15).

\section{Discussion}

We next explore factors that help explain the simulated changes to tides, storm surge and extreme discharge, using the analytical models developed for typical (nonevent) conditions.

\subsection{Interpreting Tidal and Surge Changes}

The reasons for the spatially variable changes in tidal amplitudes (e.g., Figure 7) are next explored by simplifying the analytical solution to only consider the incoming wave (i.e., the amplitude $A$ in Equation 4 is 
b)

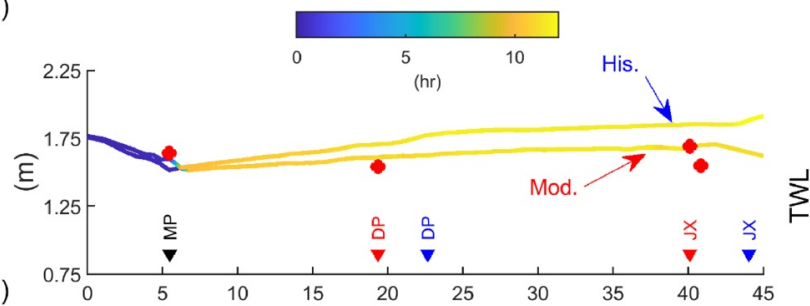

c)

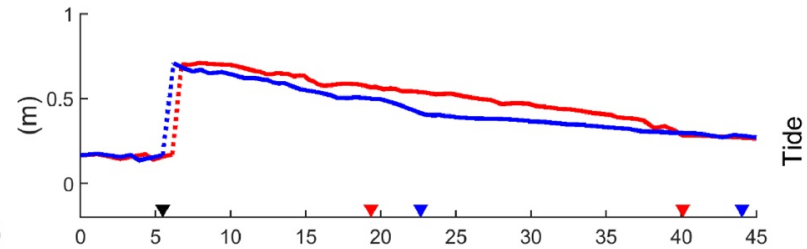

d)
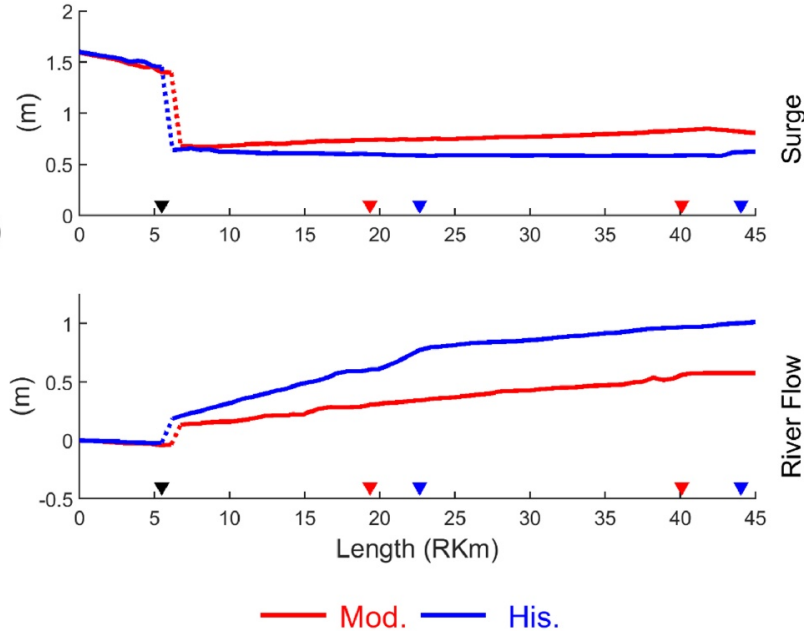

Figure 13. (a) Maximum total water level simulated during Hurricane Irma for the historical (blue) and modern (red) configuration, with the contribution of tides (b), storm surge (c) and river flow (d) to the total water level shown below. Adding (b), (c), and (d) yields the total water level (a). In (a), the color shading shows how much the time of peak water level lagged the time of peak water level at the coast. The stair-case pattern in (b), (c), and (d) results from shifts in the timing of the peak. After a time shift, the relative contributions of tidal, surge and river forcing to the peak water level have changed. In (a) MP = Mayport (black triangle); DP = Dames Point; and JX = Jacksonville. The red and blue triangles mark the modern and historical distance of Mayport and Jacksonville from the coast. set to zero); this simplification can be made because the reflected wave is a small, order $10 \%-20 \%$ correction except at bathymetric transitions. Further, we consider a constant width and depth section that is representative of near coastal bathymetry (Figures 2 and 3), and artificially extend it upstream such that tides damp out. For explanatory simplicity, we assume that the linearized friction coefficient $r$ is constant everywhere (Equation 3). Then, under highly frictional conditions in which $\frac{r}{\omega} \gg 1$, the tidal amplitude $\eta(x)$ decays exponentially as

$$
\eta(x) \approx \eta_{o} \exp (\mu x),
$$

where $\eta_{o}$ is the amplitude at the ocean boundary and the damping modulus $\mu<0$ is approximated as:

$$
\mu \approx \frac{-2}{3}\left(\frac{\omega r}{g h}\right)^{\frac{1}{2}} .
$$

Note that an additional dependence on depth $h$ also enters through $r$ (Equation 3); this solution is similar to LeBlond (1978). From Figure 6, the exponential decay in tidal amplitude is empirically estimated to be $\mu=\frac{-1}{22} \mathrm{~km}^{-1}$ (historical system) and $\mu=\frac{-1}{38} \mathrm{~km}^{-1}$ (modern system). The equivalent result is found in Equations 10 and 11 by reducing from $\frac{r}{\omega} \sim 11.5$ (historical) to $\frac{r}{\omega} \sim 7.7$ (modern), using 5 and $10 \mathrm{~m}$ as approximations for the depth of the lower $40 \mathrm{~km}$.

Following the observation that depth changes are the major cause of tidal amplitude changes (Figure 8), we next investigate how long-wave amplitudes in the simplified formulation (Equation 10) depend on depth. Specifically, the change in amplitude $\Delta \eta_{H}$ that occurs at point $x$ due to a change in depth $\Delta h$ is approximated by taking the partial derivative of Equation 10 with respect to $h$, after substituting $r=\frac{8}{3 \pi} \frac{C_{d} U_{T}}{h}$ (Equation 3) into Equation 11. For simplicity we do not consider the changes in velocity $U_{T}=\frac{Q_{T}}{b h}$ that occur due to deepening, and hold the velocity in Equation 3 constant. The modeled increase in tidal velocity of $20 \%-$ $35 \%$ in the lower $25 \mathrm{~km}$ of the estuary is relatively small compared to the doubling of depth; moreover, the damping coefficient $\mu$ (Equation 11) is more sensitive to depth variations ( $h$ dependence) than tidal velocity $\left(U_{T}^{1 / 2}\right.$ dependence). Hence, while increased tidal velocity is an important feedback effect that reduces the effect of depth changes, holding it constant is justified for scaling/interpretation purposes. Similarly, we neglect any small changes to tidal amplitudes at the ocean boundary caused by radiation damping, following the observation that $\mathrm{M}_{2}$ amplitude changes in Mayport are slight ( $\left.\sim 6 \%\right)$ compared to further upstream. We leave the effect of these and other factors (e.g., length and width changes) to future investigation.

With these simplifications, the change in tidal amplitude $\Delta \eta_{H}(x)$ due to a depth change scales as:

$$
\Delta \eta_{H}(x) \sim-\mu \eta_{o} x * \exp (\mu x) \frac{\Delta h}{h},
$$

where the leading coefficient of order (1) has been dropped. 


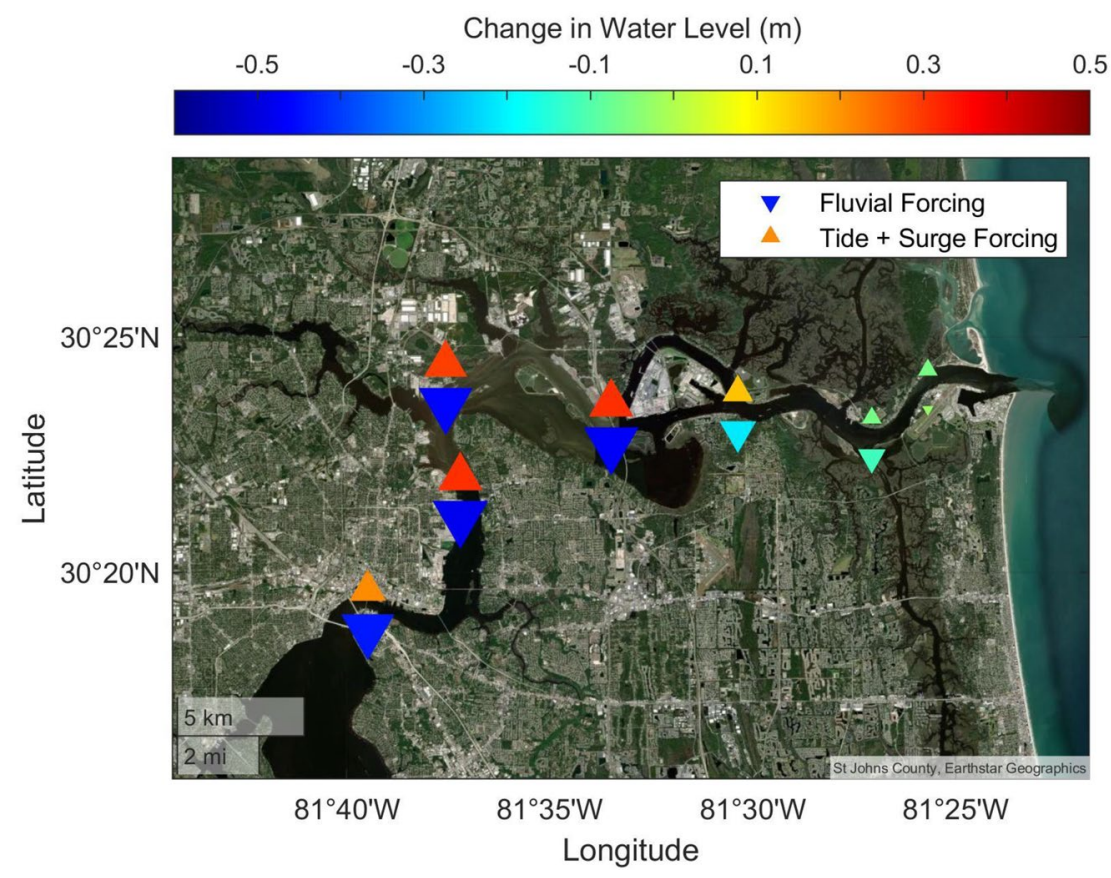

Figure 14. Simulated change to peak water level (historical-modern) caused by fluvial forcing (river discharge) and marine (tide + surge) forcing, based on Figure 13. The size of each symbol is proportional to the magnitude of the effect. Changes to fluvial and marine induced-water levels counteract each other.

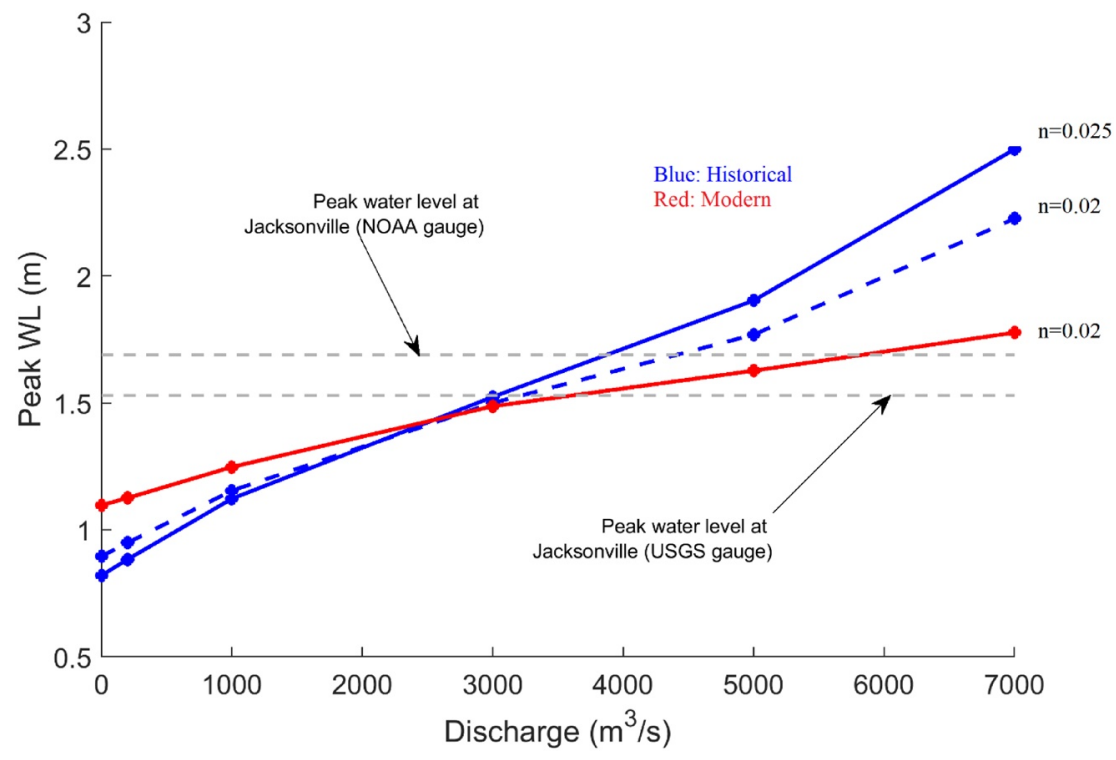

Figure 15. Simulated maximum water level at Jacksonville ( $\mathrm{Rkm} 40)$ during hurricane Irma using constant discharge at the upstream boundary, for both 1898 (Historical) and 2014 (Modern) bathymetry. The coastal boundary condition is the same as in Figures 12-14. The measured peak water level observed at the NOAA and USGS gauges in Jacksonville (1.69 and $1.54 \mathrm{~m}$ relative to the NAVD-88 datum, respectively) is indicated. The impact of changing the Manning's coefficient in the historical simulation is depicted by a solid line $(n=0.025)$ and a dashed line $(n=0.02)$. Above a discharge of $\sim 2,600 \mathrm{~m}^{3} / \mathrm{s}$, water levels in Jacksonville in the historical simulation exceed the modern simulation. 
Despite the many simplifications and restrictions discussed above, several insights into the observed pattern of tidal change within the estuary follow from this analysis:

- Amplitude changes $\Delta \eta_{H}$ are related to the percentage change in depth; in the Saint Johns River Estuary, depth increases have dominated historically over other modifications, since $\frac{\Delta h}{h} \approx 2$ is quite large. The analytical dependency of tidal evolution on $\frac{\Delta h}{h}$ also suggests that tides become progressively less sensitive to the same incremental change $\Delta h$ in deep waters, as opposed to shallow waters.

- The function $x * \exp (\mu x)$ increases as one moves landward, reaches a maximum, and thereafter asymptotes toward zero. Hence, for an estuary described by the simplified model above, changes are predicted to be small at the estuary mouth $(x=0)$ and far upstream $\left(x \gg-\frac{1}{\mu}\right)$. In between, there is a location with maximum sensitivity to altered depth. Both in-situ and modeled results follow this pattern (Figures 6 and 7), and its influence is also observed in peak water levels (Figure 14). Similar to the Saint Johns River, other studies have also found that the maximum increase in tidal amplitudes is found within estuarine regions marked by a strong damping of tidal amplitudes. This distinguishes a highly damped estuary from an estuary with a total reflection, since in that case the maximum change often occurs near the head of tides (Talke \& Jay, 2020; Winterwerp et al., 2013).

- The location of maximum change, $x_{\max }$, occurs around the e-folding scale for damping, $L_{\text {damping }}=\frac{-1}{\mu}$. In the Saint Johns Estuary, the maximum change in tidal amplitudes-that is, $x_{\max }$-is located between 20 and $25 \mathrm{~km}$ from the coast. This is approximately equal to the observed e-folding scale for damping in historical tide data.

The simplifications in Equations 10-12 means that they only qualitatively approximate real behavior. More complex approaches (e.g., Li et al., 2016) are required to assess the effects of cross-sectional variability, off-channel storage, and other system features. Still, the spatial change in tidal amplitudes suggested by Equation 12 is not dissimilar to those noted in Figures 6 and 7. Interestingly, storm surge changes appear to follow a similar pattern, with a simulated maximum that is nearly co-located with the position of maximum tide change (Figures 12b, and 14); more research is needed. A similar location for maximum change in total water level magnitudes was modeled by USACE (2014) for a 50 years and 100 years storm event and an increase in depth from a $12.2 \mathrm{~m}$ (40 ft.) to a $14.3 \mathrm{~m}$ (47 ft.) channel. Changes to tidal amplitudes and the scaling in Equation 12 may therefore provide insights into the spatial pattern of storm surge changes (see also Familkhalili et al., 2020).

\subsection{Interpreting Subtidal Change}

The analytical model for mean water level is consistent with the changes simulated by the Delft3D numerical model at low flow (Figure 10), and provides insights into the factors that may influence subtidal change. Specifically, the subtidal slope term, $\alpha \sim \frac{C_{d} Q_{R} U_{T}}{g b h^{2}}$ (Equation 9), suggests that factors such as increased depth and decreased drag coefficient may reduce the modeled subtidal water levels. These factors appear to be partially counteracted by decreased width (through diking of wetlands) and increased tidal discharge and tidal velocity. Further, the observed shift in subtidal water levels is a function of discharge, $Q_{R}$ (Figure 13). Therefore, any change in water levels caused by river discharge may become more prominent during river flood conditions (see Figures 12-15), though overbank flow effects must be considered (see e.g., Helaire et al., 2019).

The approximate agreement between Equation 9 and empirical measurements (Figure 10) highlights the role that tidal velocity may have in setting mean water levels. The semi-analytical tide model suggests that a 20\%-35\% increase in tidal velocity occurred between the historical and modern configurations between 0 and $30 \mathrm{~km}$ from the estuary mouth. In the upper Scheldt, historical trends in tidal velocity also served to increase the subtidal slope in water level (Wang et al., 2019). The role of tidal velocity contrasts with large river systems such as the Mississippi, in which tides are small and thus neglected in models of the subtidal water level curve (e.g., Nittrouer et al., 2012). 
A qualitatively similar decrease in mean water levels due to channel deepening has been observed or modeled in other systems, including the Hudson River (Ralston et al., 2019), the Columbia River (Helaire et al., 2019; Jay et al., 2011), and the Ems River (Jensen et al., 2003). These observations were made between 100 and $250 \mathrm{~km}$ from the open coast, where the integrated effect of small changes in the slope of surface water level becomes more obvious. The modeled drop in the water level difference between Jacksonville and the estuary inlet between historical and modern conditions is small (Figure 10), except during extreme floods (Figure 15), and is qualitatively consistent with available in-situ data during average discharge conditions (Figure 10).

The flooding caused by river discharge during hurricane Irma is a low probability event. Only one other river discharge event besides hurricane Irma exceeded 3,000 $\mathrm{m}^{3} / \mathrm{s}$ since 1988 (September 2004). More than half of the annual peak discharges measured in Jacksonville range between 1,000 and 1,600 $\mathrm{m}^{3} / \mathrm{s}$. Therefore, the large effect of bathymetric changes on the water levels induced by fluvial effects during Irma (Figures 12-15) is unusual. Under more typical discharge conditions, a storm surge with a comparable magnitude to hurricane Irma would likely produce a larger water level today, than historically, particularly if phased together with tides (Figure 15).

\subsection{Comparison With Other Studies and Sources of Uncertainty}

Our results are generally consistent with past modeling efforts. The large effect of fluvial forcing is consistent with Bacopoulos, Kubatko, et al., 2017, Bacopoulos, Tang, et al., 2017, who found that run-off from Tropical Storm Fay (2008) added $\sim 0.5 \mathrm{~m}$ to the simulated storm tide. Similarly, modeling has suggested that the stormtide (surge + tides) measured in/near the shipping channel during a 100 year event would increase by up to $0.2 \mathrm{~m}$, after deepening from 12.2 to $14.3 \mathrm{~m}$ (40-47 ft.; USACE, 2014). Nonetheless, since the timing of a storm surge relative to tides and the river hydrograph may shift in each event, the modeled response to system changes may vary. For example, Bilskie (2013) found a negligible change in total water levels when hurricane Dora was modeled for both 12.2 and $14.3 \mathrm{~m}$ channels. As shown by Familkhalili and Talke (2016), greater tide magnitudes can reduce or negate the effect of an amplified storm surge, if the storm peak is timed at low water. Therefore, an approach that considers a full range of different storm tracks, magnitudes, rainfall, and tides is likely needed, to fully assess changes to flood hazard caused by channel deepening (e.g., Orton et al., 2020).

Our approach yields reasonable results that explain changes to empirically measured tides. However, the interaction of estuary tides with the open ocean can produce changes at the ocean boundary (e.g., radiation effects) which we do not consider analytically. Similarly, a drawback of the storm-surge hydrograph method used here is that storm surge magnitudes can vary along the ocean boundary due to meteorological forcing (e.g., Dietsche et al., 2007). The (likely small) errors that are introduced by assuming a constant storm surge elevation along the ocean boundary are present in both the historical and modern models, and therefore have little effect on their comparison.

The good correspondence between analytical and numerical results (for tides and mean water levels) under average conditions suggests that channel deepening is the major cause of changed numerical results; however, this inference has not been rigorously tested with one-at-a-time variations in numerical model bathymetry and forcing (depth, wetland connectivity, surge variability, etc.). Moreover, the analytical result represents a simplified system with idealized bathymetric variation and no wetlands; these factors may explain why the friction coefficients used in the analytical model were larger than in the numerical model. Many additional factors have not been considered. For example, we do not directly model changes to local setup caused by local wind, though these may to some extent modeled through using a virtual discharge boundary condition (see Section 2.5). Many additional factors beyond channel deepening and shortening likely influence flood heights in Jacksonville. For example, we do not analyze the effect of the entrance jetties. Over the past century, the watershed around Jacksonville has become more urban, and natural streams have been channelized, both tending to make the run-off response more immediate. We do not consider the effect of such land-use changes. Other factors, such as barometric pressure variations and salinity intrusion, also influence water level patterns (Bacopoulos et al., 2009; Mulamba et al., 2019; Orton et al., 2012). Nonetheless, the simulated decrease in river discharge effects during hurricane Irma (Figures 12-15) is con- 
sistent with observations of decreased water level during low flow conditions (Figures 9 and 10) and with analytical scaling (Equation 9). Similarly, the amplification in simulated surge is consistent with observations and analytical models of tides. Hence, our results suggest a substantial change in barotropic dynamics within the Saint Johns River Estuary, with corresponding effects on flood hazard.

\section{Conclusions}

In this contribution, we investigate how channel deepening, shortening and other modifications alter the way tides, storm surge, and river discharge flow through hyposynchronous estuaries marked by tides that strongly decay in the landward direction. The results suggest that long-wave amplitudes in estuarine regions marked by strong damping are quite sensitive to changes in depth. These changes manifest in a spatially variable way, with a maximum that is located near the observed damping length-scale for tides. Subtidal water levels, by contrast, are predicted to decrease due to the same channel deepening. These predictions are tested in the Saint Johns River Estuary, Florida, an estuary in which depths have approximately doubled, width decreased, and the shipping channel shortened since the 1890s. Both in-situ, numerical, and analytical results indicate that tidal amplitudes and tidal discharges have increased, and in many locations doubled, in response to channel dredging and to a lesser extent width, length, and drag coefficient changes. Storm surge has also increased. Nonetheless, modeled subtidal water levels have decreased, particularly during extreme flood flows. As a result, hurricane Irma likely would have caused higher water levels, had it occurred in 1898.

Since many estuary regions are highly frictional and marked by a strong damping in tides (e.g., Talke \& Jay, 2020 review, and references therein), the spatially variable changes to tides and surge observed in the Saint Johns River Estuary likely occurs in other locations. An implication is that flood hazard may be shifting in a spatially non-uniform way over time, due both to changes in long-waves and subtidal water levels. As was also observed by Ralston et al. (2019) for Albany, New York, larger tides and storm surge magnitudes in a modern system can paradoxically be correlated with less flooding than would have occurred historically, at least for the event considered here. Nonetheless, Jacksonville is probably more at risk to flooding from large hurricane surge than it was historically. Effectively, as in the Cape Fear Estuary (see Familkhalili \& Talke, 2016), the natural protection afforded by shallow channels has been largely removed, making inland regions much more exposed to marine-sourced flooding. In estuaries and tidal rivers, therefore, studies that evaluate changing flood hazard must consider the (often competing) sum of river, tidal and surge effects.

\section{Data Availability Statement}

As described in Methods Section 2.2, many of the historical records used here are available from the EV2 (https://www.ncdc.noaa.gov/EdadsV2/), USGS, or NOAA databases. The other archival tide records are available in Record Group 23 at the US National Archives in College Park, Maryland (accession number RG 23, UD-WW Entry 14). Selected pictures and descriptions of important archival data and meta-data are included in the Supplemental Information. Additionally, tidal records from Mayport (1895-1897) and Longbranch (1929-1935) are available at the PDX Scholar website (https://pdxscholar.library.pdx.edu/ cengin_data/5/, http://doi.org/10.15760/cee-data.05).

\section{Acknowledgments}

Funding was provided by the National Science Foundation (Award number 1455350 and 2013280). The many students who helped digitize records are sincerely thanked. We also thank Henk Schuttelaars, Arnoldo Valle-Levinson, and two additional anonymous reviewers for their helpful comments, which greatly improved the quality of the manuscript.

\section{References}

Bacopoulos, P., Funakoshi, Y., Hagen, S. C., Cox, A. T., \& Cardone, V. J. (2009). The role of meteorological forcing on the St. Johns River (Northeastern Florida). Journal of Hydrology, 369, 55-70. https://doi.org/10.1016/j.jhydrol.2009.02.027

Bacopoulos, P., Hagen, S. C., Cox, A. T., Dally, W. R., \& Bratos, S. M. (2012). Observation and simulation of winds and hydrodynamics in St. Johns and Nassau Rivers. Journal of Hydrology, 420-421, 391-402. https://doi.org/10.1016/j.jhydrol.2011.12.032

Bacopoulos, P., Kubatko, E. J., Hagen, S. C., Cox, A. T., \& Mulamba, T. (2017a). Modeling and data assessment of longitudinal salinity in a low-gradient estuarine river. Environmental Fluid Mechanics, 17, 323-353. https://doi.org/10.1007/s10652-016-9486-8

Bacopoulos, P., Tang, Y., Wang, D., \& Hagen, S. C. (2017b). Integrated hydrologic-hydrodynamic modeling of estuarine-riverine flooding: 2008 Tropical storm fay. Journal of Hydrologic Engineering, 22(8). https://doi.org/10.1061/(ASCE)HE.1943-5584.0001539

Bellino, J. C., \& Spechler, R. M. (2013). Potential effects of deepening the Saint Johns River navigation channel on saltwater intrusion in the surficial aquifer system, U.S. Geological Survey Scientific Investigations Report 2013-5146, 34 p. https://doi.org/10.3133/sir20135146 
Bilskie, M. V., (2013). Hydrodynamic modeling of tides and hurricane storm surge for pre- and post-dredging conditions in the Lower St. Johns River, Florida. American Society of Civil Engineers Coasts, Oceans, Ports, and RIvers PORTS '13, 1955-1964. https://doi. org/10.1061/9780784413067.200

Blewitt, G., Hammond, W., \& Kreemer, C. (2018). Harnessing the GPS data explosion for interdisciplinary science. Eos, 99. https://doi. org/10.1029/2018EO104623

Burchard, H., Schuttelaars, H. M., \& Ralston, D. K. (2018). Sediment trapping in estuaries. Annual Review of Marine Science, 10(1), 371395. https://doi.org/10.1146/annurev-marine-010816-060535

Buschman, F. A., Hoitink, A. J. F., van der Vegt, M., \& Hoekstra, P. (2009). Subtidal water level variation controlled by river flow and tides Water Resources Research, 45(10), W10420. https://doi.org/10.1029/2009WR008167

Cangialosi, J. P., Latto, A. S., \& Berg, R. (2018). National Hurricane Center Tropical Cyclone Report: Hurricane Irma. NOAA, AL112017. https://www.nhc.noaa.gov/data/tcr/AL112017_Irma.pdf

Deltares (2014). Delft3D-FLOW Simulation of multi-dimensional hydrodynamic flows and transport phenomena, including sediments: User Manual. Deltares, in Delft, The Netherlands.

Dietsche, D., Hagen, S. C., \& Bacopoulos, P.(2007). Storm surge simulations for hurricane hugo(1989): On the significance of inundation areas Journal of Waterway, Port, Coastal, and Ocean Engineering, 133(3), 183-191. https://doi.org/10.1061/(ASCE)0733-950X(2007)133:3(183)

Dronkers, J. J. (1964). Tidal Computations in Rivers and Coastal Waters. New York: Wiley. ISBN-13 : $978-0720416121$.

Familkhalili, R., \& Talke, S. A. (2016). The effect of channel deepening on tides and storm surge: A case study of Wilmington, NC. Geophysical Research Letters, 43, 9138-9147. https://doi.org/10.1002/2016GL069494

Familkhalili, R., Talke, S. A., \& Jay, D. A. (2020). Tide-storm surge interactions in highly altered estuaries: How channel deepening increas es surge vulnerability. Journal of Geophysical Research Oceans, 125(4), e2019JC015286. https://doi.org/10.1029/2019JC015286

Friedrichs, C. T., \& Aubrey, D. G. (1994). Tidal propagation in strongly convergent channels. Journal of Geophysical Research, 99(C2), 3321-3336. https://doi.org/10.1029/93JC03219

Friedrichs, C. T., \& Madsen, O. S. (1992). Nonlinear diffusion of the tidal signal in frictionally dominated embayments. Journal of Geophysical Research, 97(C4), 5637-5650. https://doi.org/10.1029/92JC00354

Giese, B. S., \& Jay, D. A. (1989). Modeling tidal energetics of the Columbia River Estuary. Estuarine, Coastal and Shelf Science. 29(6), 549-571). https://doi.org/10.1016/0272-7714(89)90010-3

Gieseler, E. A. (1893). Report of Mr. E.A. Gieseler, assistant engineer, upon the gauging of the St, Johns River. Volume II, appendix O1 of the annual report of the Chief of Engineers, United States Army, to the secretary of war, for the year 1893 (pp. 1613-1646). Washington, DC Government Printing Office.

Godin, G. (1999). The propagation of tides up rivers with special considerations on the Upper Saint Lawrence River. Estuarine, Coastal and Shelf Science, 48(3), 307-324. https://doi.org/10.1006/ecss.1998.0422

Hagen, S. C., Morris, J. T., Bacopoulos, P., \& Weishampel, J. F. (2013). Sea-level rise impact on a salt marsh system of the Lower St. Johns River. Journal of Waterway, Port, Coastal, and Ocean Engineering, 139(2). https://doi.org/10.1061/(ASCE)WW.1943-5460.0000177

Helaire, L. T., Talke, S. A., Jay, D. A., \& Mahedy, D. (2019). Historical changes in Lower Columbia River and estuary floods: A numerical study. Journal of Geophysical Research Oceans, 124(11), 7926-7946. https://doi.org/10.1029/2019JC015055

Henrie, K., \& Valle-Levinson, A. (2014). Subtidal variability in water levels inside a subtropical estuary. Journal of Geophysical Research Oceans, 119, 7483-7492. https://doi.org/10.1002/2014JC009829

Horsburgh, K. J., \& Wilson, C. (2007). Tide-surge interaction and its role in the distribution of surge residuals in the North Sea. Journal of Geophysical Research, 112, C08003. https://doi.org/10.1029/2006JC004033

Jay, D. A. (1991). Green's law revisited: Tidal long-wave propagation in channels with strong topography. Journal of Geophysical Research, 96, 20585-20598. https://doi.org/10.1029/91JC01633

Jay, D. A., Leffler, K., \& Degens, S. (2011). Long-term evolution of Columbia River tides. Journal of Waterway, Port, Coastal, and Ocean Engineering, 137, 182-191. https://doi.org/10.1061/(ASCE)WW.1943-5460.0000082

Jensen, J., Mudersbach, C., \& Blasi, C. (2003). Hydrological changes in tidal estuaries due to natural and anthropogenic effects. 6th International MEDCOAST 2003 Conference.

Kästner, K., Hoitink, A. J. F., Torfs, P. J. J. F., Deleersnijder, E., \& Ningsih, N. S. (2019). Propagation of tides along a river with a sloping bed. Journal of Fluid Mechanics, 872, 39-73. https://doi.org/10.1017/jfm.2019.331

Kingman, D. C., Zinn, G. A., \& McClure, J. (1915). Index to the reports of the chief of Engineers, U.S. Army (including the reports of the Isthmian canal commission, 1899-1914): 1866-1912. Volume I-Rivers and Harbors. Document 740, House of Representatives, 63rd Congress. Washington DC, U.S. Government Printing Office.

Kukulka, T., \& Jay, D. A. (2003a). Impacts of Columbia River discharge on salmonid habitat: 1. A nonstationary fluvial tide model. Journal of Geophysical Research, 108, C9. https://doi.org/10.1029/2002JC001382

Kukulka, T., \& Jay, D. A. (2003b). Impacts of Columbia River discharge on salmonid habitat: 2. Changes in shallow-water habitat. Journal of Geophysical Research, 108, C9. https://doi.org/10.1029/2002JC00182910.1029/2003jc001829

LeBlond, P. H. (1978). On tidal propagation in shallow rivers. Journal of Geophysical Research, 83(C9), 4717. https://doi.org/10.1029/ JC083iC09p04717

Li, C., Schuttelaars, H. M., Roos, P. C., Damveld, J. H., Gong, W., \& Hulscher, S. J. M. H. (2016). Influence of retention basins on tidal dynamics in estuaries: Application to the Ems estuary. Ocean \& Coastal Management, 134, 216-225. https://doi.org/10.1016/j. ocecoaman.2016.10.010

Moftakhari, H. R., Jay, D. A., Talke, S. A. (2016). Estimating river discharge using multiple-tide gages distributed along a channel. Journal of Geophysical Research, Oceans, 121(4), 2078-2097. https://doi.org/10.1002/2015JC010983

Monroe, N., \& Hong, C. (2018). As the ocean creeps in. The Florida Times-Union. http://gatehousenews.com/riverproject/home/site/jacksonville.com

Monthly Weather Review (MWR), (1898). Volume XXVI, No. 10, Editor, C. Abbe,. ISSN: 0027-0644; eISSN: $1520-0493$.

Mulamba, T., Bacopoulos, P., Kubatko, E. J., \& Pinto, G. F. (2019). Sea-level rise impacts on longitudinal salinity for a low-gradient estuarine system. Climatic Change, 152, 533-550. https://doi.org/10.1007/s10584-019-02369-x

Nittrouer, J. A., Shaw, J., Lamb, M. P., \& Mohrig, D. (2012). Spatial and temporal trends for water-flow velocity and bed-material sediment transport in the lower Mississippi River. Geological Society of America Bulletin, 124(3-4), 400-414. https://doi.org/10.1130/B30497.1

Orton, P., Georgas, N., Blumberg, A., \& Pullen, J. (2012). Detailed modeling of recent severe storm tides in estuaries of the New York City region. Journal of Geophysical Research, 117, C09030. https://doi.org/10.1029/2012JC008220

Orton, P. M., Sanderson, E. W., Talke, S. A., Giampieri, M., \& MacManus, K. (2020). Storm tide amplification and habitat changes due to urbanization of a lagoonal estuary. Natural Hazards and Earth System Sciences, 20, 2415-2432. https://doi.org/10.5194/nhess-20-2415-2020 
Pareja-Roman, L. F., Chant, R. J., \& Sommerfield, C. K. (2020). Impact of historical channel deepening on tidal hydraulics in the delaware estuary. Journal of Geophysical Research: Oceans, 125(12), e2020JC016256. https://doi.org/10.1029/2020JC016256

Pawlowicz, R., Beardsley, B., \& Lentz, S. (2002). Classical tidal harmonic analysis including error estimates in MATLAB using T_TIDE. Computers \& Geosciences, 28, 929-937. https://doi.org/10.1016/S0098-3004(02)00013-4

Ralston, D. K., \& Geyer, W. R. (2019). Response to channel deepening of the salinity intrusion, estuarine circulation, and stratification in an urbanized estuary. Journal of Geophysical Research Oceans, 124, 4784-4802. https://doi.org/10.1029/2019JC015006

Ralston, D. K., Talke, S., Geyer, W. R., Al-Zubaidi, H. A. M., \& Sommerfield, C. K. (2019). Bigger tides, less flooding: Effects of dredging on barotropic dynamics in a highly modified estuary. Journal of Geophysical Research Oceans, 124, 196-211. https://doi. org/10.1029/2018JC014313

Rawls, O. G. (1952). Case history of Saint Johns River and Jacksonville Harbor, Florida. Proceedings of the International Conference on Coastal Engineering, 613(3).

Sandrik, A. \& Jarvinen, B. ( 1999). A Reevaluation of the Georgia and Northeast Florida Tropical Cyclone of 2 October 1898. Pre-prints 23rd Conference on Hurricanes and Tropical Meteorology. (Vol I), 10-15, 475-478.

Shen, J., Wang, H., Sisson, M., \& Gong, W. (2006). Storm tide simulation in the Chesapeake Bay using an unstructured grid model. Estuarine, Coastal and Shelf Science, 68(1), 1-16. https://doi.org/10.1016/j.ecss.2005.12.018

Talke, S. A. \& Jay, D. A. (2017). Archival water-level measurements: Recovering historical data to help design for the future. US Army Corps of Engineers: Civil Works Technical Series, Report CWTS-02, 49.

Talke, S. A., \& Jay, D. A. (2020). Changing tides: The role of natural and anthropogenic factors. Annual Review Marine Science, 12, $121-151$. https://doi.org/10.1146/annurev-marine-010419-010727

United States Army Corps of Engineers (USACE). (1879). Annual report of the secretary of war for the year 1879, Volume II, Part 2, report of the chief of Engineers (pp. 766-792). DC Government Printing Office. Appendix I-7.

United States Army Corps of Engineers (USACE). (1892). Annual Report of the Chief of Engineers, United States Army, to the Secretary of War, for the Year 1892 (Vol. II, pp. 1349-1366). DC Government Printing Office. Appendix O1.

United States Army Corps of Engineers Jacksonville District. (2014). Final integrated general reevaluation report II and supplemental environmental impact statement. Jacksonville Harbor, Duval County, Florida. Appendix A, Attachment J. P1623 1646.

Valle-Levinson, A., Olabarrieta, M., \& Valle, A. (2013). Semidiurnal perturbations to the surge of Hurricane Sandy. Geophysical Research Letters, 40, 2211-2217. https://doi.org/10.1002/grl.50461

Wang, Z. B., Vandenbruwaene, W., Taal, M., \& Winterwerp, H. (2019). Amplification and deformation of tidal wave in the Upper Scheldt Estuary. Ocean Dynamics, 69, 829-839. https://doi.org/10.1007/s10236-019-01281-3

Winterwerp, J. C., \& Wang, Z. B. (2013). Man-induced regime shifts in small estuaries-I: Theory. Ocean Dynamics, 63, 1279-1292. https:// doi.org/10.1007/s10236-013-0662-9

Winterwerp, J. C., Wang, Z. B., van Braeckel, A., van Holland, G., \& Kösters, F. (2013). Man-induced regime shifts in small estuaries-II: A comparison of rivers. Ocean Dynamics, 63(11-12), 1293-1306. https://doi.org/10.1007/s10236-013-0663-8

$\mathrm{Xu}, \mathrm{S} .$, \& Huang, W. (2014). An improved empirical equation for storm surge hydrographs in the Gulf of Mexico, U.S.A. Ocean Engineering, 75, 174-179. https://doi.org/10.1016/j.oceaneng.2013.11.004 